\title{
The use of ultrasound to release chemotherapeutic drugs from micelles and liposomes
}

\author{
Salma E. Ahmed, Ana M. Martins, and Ghaleb A. Husseini \\ Department of Chemical Engineering, American University of Sharjah, Sharjah, United Arab Emirates
}

Abstract

Several drug delivery systems have been investigated to reduce the side effects of chemotherapy by encapsulating the therapeutic agent in a nanosized carrier until it reaches the tumor site. Many of these particles are designed to be responsive to the mechanical and thermal perturbations delivered by ultrasound. Once the nanoparticle reaches the desired location, ultrasound is applied to release the chemotherapy drug only in the vicinity of the targeted (cancer) site, thus avoiding any detrimental interaction with healthy cells in the body. Studies using liposomes and micelles have shown promising results in this area, as these nanoparticles with simple, yet effective structures, showed high efficiency as drug delivery vehicles both in vitro and in vivo. This article reviews the design and application of two novel nanosized chemotherapeutic carriers (i.e. micelles and liposomes) intended to be actuated by

ultrasound.

\section{Introduction}

The increasing demand for the development of new drug delivery systems (DDS) has increased due to the need to reduce undesirable side effects caused by drug agents that affect both diseased and healthy tissues, and the fact that this uncontrolled release leads to a higher consumption of medications which is neither economic nor beneficial [1]. Nano-therapy and nanocarriers have been developed as a result of current advances in nanotechnology, and these new "smart" DDS can be targeted towards certain sites and organs and triggered to release the drug whenever needed, using internal and external stimuli [2-4].

Liposomes are considered among the best known nanocarriers. They have proven to be one of the most promising DDS, because their structure is similar to biological membranes and also for the possibility of their use in a wide range of applications by utilizing their varying compositions, colloidal behavior, surface charge and methods of preparation [5]. Liposomes have a high drug-loading efficiency, which can reach up to $0.25 \mathrm{mg} \mathrm{drug} / \mathrm{mg}[6]$ and they have the capability of holding agents with different solubilities, whether they are hydrophilic, hydrophobic or a combination of both [7]. All these properties allow liposomes to be extensively researched for clinical applications [8]. ghusseini@aus.edu solubilization [9-11].

\author{
Keywords \\ Doxorubicin, drug delivery systems, \\ nanocarriers, NanoDeliv, Pluronic, \\ targeting, ultrasound
}

History

Received 2 April 2014

Revised 20 July 2014

Accepted 8 August 2014

Published online 9 September 2014

Address for correspondence: Ghaleb A. Husseini, Department of Chemical Engineering, American University of Sharjah, PO Box 26666, Sharjah, United Arab Emirates. Tel: +971-6-515 2970. E-mail:

On the other hand, micelles, although not yet widely utilized clinically, also have several advantages: (i) they are easy to prepare and load with drug agents; (ii) they are biocompatible; (iii) they possess high, although limited stability in biological fluids; (iv) it is possible to control the drug release from their inner hydrophobic core; and (v) they can be used in drug

These characteristics form the basis of scientific and industrial applications of liposomes and micelles and their importance as DDS in chemotherapy has been selected as the focus of this paper. The use of other nanocarriers, such as microbubbles, microbubble hybrids, and phase change agents, used as DDS in conjunction with US, have been recently reviewed elsewhere [12].

The chemotherapeutic agent Doxorubicin (Dox) is one of the most widely used drugs in cancer treatment that is based on the concept of suppressing tumor growth. Dox is an anthracycline antibiotic that has high anti-tumor activity against numerous types of cancer, especially breast and ovarian cancers $[13,14]$, as well as hematological malignancies [15]. It is also considered among the most efficacious agents in the treatment of AIDS-related Kaposi's sarcoma [16] and solid tumors that arise in the bile ducts, endometrial tissue, the esophagus and liver, osteosarcomas, soft-tissue sarcomas and non-Hodgkin's lymphoma [17]. Dox affects the uncontrollable division of cells, by inhibiting the activity of topoisomerase II, 
2 S. E. Ahmed et al.

which prevents the replication of cellular DNA and RNA [17], thus stopping cancer proliferation. However, Dox has high cardiotoxicity, causing damage to the myocardium. Early effects of Dox administration include acute left ventricular dysfunction and arrhythmias and, with repeated use, dilated cardiomyopathy was observed that can eventually lead to druginduced congestive heart failure and is fatal in approximately $50 \%$ of cases $[18,19]$. Other acute side effects of Dox include neutropenia, nausea, arrhythmias, vomiting and alopecia [20].

Encapsulation of Dox and other anti-tumor drugs in liposomes and micelles (especially polymeric micelles) alters the pharmacokinetics and distribution of those agents and thus reduces their cytotoxicity [21-23]; therefore it is important to consider sequestering the drugs inside these drug delivery vehicles in a concentration and counterion-dependent manner [8,24-26].

In the following sections we will discuss the use of liposomes and micelles as therapeutic agents' carriers and ultrasound (US) as a trigger mechanism, for Dox and other drugs.

\section{Ultrasound}

Ultrasound consists of pressure waves with frequencies that are higher than the upper limit of the human audible range, i.e. higher than $20 \mathrm{kHz}$ [27]. In particular, US used for diagnosis and therapeutic purposes has frequencies in the range of 0.8 to $3 \mathrm{MHz}$ [28]. Therapeutic US uses waves that can be easily focused, reflected, refracted, and propagated through a medium, hence it can be targeted toward certain cells and tissues [8,29].

Ultrasound waves can be generated using piezoelectric transducers, which convert the applied voltage wave forms into mechanical forms, namely the US waves [30]. Ultrasonic waves can be classified into low- and high- intensity US, according to the power densities employed [31]. The ultrasonic devices used in medicine are composed of a generator that delivers a high-frequency alternating current, and a transducer which converts the current into acoustic vibrations [28]. Additionally it has been shown that, for medical purposes, the use of pulsed US is more favorable than continuous waves (CW) since the former causes less negative biological interactions with healthy cells and tissues not intended for treatment [32]. When US is used as a trigger, it is focused on the drug carriers once they reach their target so that the drug is released and penetrates into the desired areas [33]. Additionally, research has shown that as the frequency is lowered, the transdermal transport and cell penetration are enhanced [34].

Ultrasound causes thermal and non-thermal effects when interacting with biological systems. The hyperthermia induced by US is associated with the absorption of acoustic energy by fluids or tissues, and occurs due to an increase in power density when the US beam is focused on a target tissue (for reviews see [27,35-40]). In targeted drug delivery strategies, hyperthermia has the added therapeutic effects of heating the drug carriers, the drugs and/or the treated tissues [41].
J Drug Target, Early Online: 1-33

Additionally, hyperthermia induced by the application of US is used in the medical field as an adjuvant in cancer chemotherapy [36-38,40,42] and in physical therapy for warming tissues [35].

The non-thermal effects of US are usually related to oscillating or cavitating bubbles and, to a lesser extent, to noncavitating effects (e.g. radiation pressure, radiation torque, and acoustic streaming) [39]. Acoustic cavitation is the interaction of acoustic waves with gas bubbles, as described by Leighton [27]. As US excites gas bubbles, the latter oscillate in response to the surrounding oscillating pressure. When the acoustic amplitude is low, the bubbles oscillate at the same frequency as the applied US waves, with relatively small change in size, while bubbles having a natural resonance similar to the frequency of the US field will achieve highest amplitudes. This is called stable or noninertial cavitation, and during this period, the bubbles accumulate dissolved gas from the liquid medium and their size increases (Figure 1). Additionally, the oscillation causes the fluid to flow around the bubble - a process called microstreaming, with velocities and shear rates that are proportional to the oscillation amplitude [43-45].

As the acoustic pressure increases or as the size of the bubble approaches the resonance size, the oscillations become non-linear, and eventually result in the total collapse of the bubble, a process called inertial, transient or collapse cavitation (Figure 1). The collapse of the bubble results in small bubbles which serve as new cavitation nuclei, which grow in size and eventually also collapse, causing shock waves. These create pressures of about 100atm in magnitude and increase the local temperature significantly, leading to the generation of free radicals [46-48]. Taken together, these processes produce considerable stress on cells, leading to the damage of the cell membrane and other organelles. Additionally, the collapse of the bubble may be asymmetrical if occurring near a blood vessel wall, a large cell, a semi-rigid vesicle, or other solid surfaces, ejecting a liquid jet at sonic speeds capable of piercing the surface [46]. It has been described that, at high amplitudes, the associated shear forces can cause the lysis of red blood cells [49] and shear open liposomes and micelles [44]. Concerning drug delivery, the biological effects associated with cavitating bubbles may increase drug interaction with the cells by physically shearing the cell membrane, which allows the direct entrance of the drug into the cytosol by simple diffusion, and/or through the upregulation of stress response pathways [49-51].

Until recently, the non-cavitating effects were not considered to be widely involved in the drug delivery process, except for increasing the convection and transport of the drug towards or into the cell. This effect was thought to be caused by the fluid or particle motion induced by acoustic streaming or radiation pressure [39]. Recently, however, Oerlemans et al. [52] argued that the release of calcein from liposomes during sonication using high-intensity focused US (HIFU), is not due to hyperthermia or transient cavitation, but is rather due to the high shear forces generated as a shock wave propagates through the medium. 
DOI: 10.3109/1061186X.2014.954119

The US technology is generally regarded as safe and cost effective, being broadly applied in the biomedical area because of its non-invasive nature. It also has the ability to penetrate deep in the body and to increase the permeability of cell membranes, thus increasing the penetration of drugs and drug carriers due to the thermal and non-thermal effects described previously [8,53-56]. Other beneficial aspects of US use in medicine include the improvement of the efficacy of thrombolytic drugs, the enhancement of the anti-tumor activity of anti-neoplastic drugs (especially for ovarian

Figure 1. Stable and transient cavitation. (A) Stable cavitation: microbubble oscillates due to the acoustic pressure causing convection microstreams at low power, non-resonant frequency. (B) Inertial cavitation: microbubble reaches resonance size at high power then collapses producing microstreams, cavitation nuclei and shockwaves with high temperatures and pressures.
Release of chemotherapeutic drugs from micelles \& liposomes 3

Numerous in vivo and in vitro studies have shown that liposomal and micellar delivery systems reduce the cardiotoxicity and other side effects associated with conventional chemotherapy, while still allowing for the extravasation of the therapeutic agent [66-71]. It is worth emphasizing that these results cannot be extended to all types of cancer, hence the need still exists for a continuous effort to synthesize liposomes and micelles that can escape the action of macrophages and other immune system elements, and hence be used in the treatment against a wide variety of cancers [7].
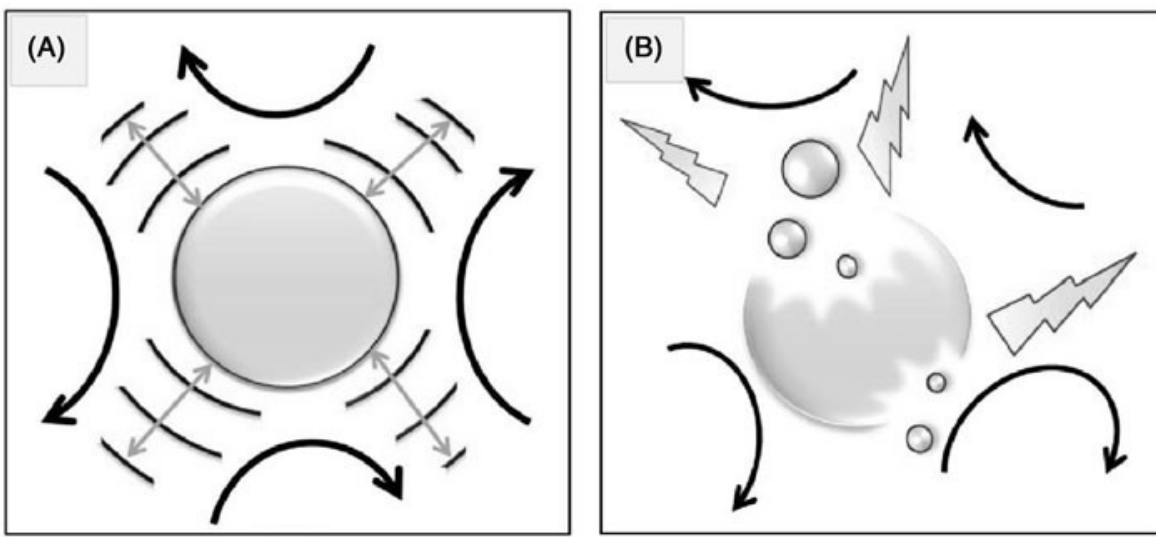

cancer), and an increase in transdermal drug delivery and gene therapy $[30,47,57,58]$.

\section{Nano-carriers}

The current advances in material science and bioengineering encouraged the application of nano-scale technologies to medicine; nanocarriers (or nano-encapsulation systems) have been introduced as promising vehicles in drug delivery. In such systems, drugs and bio-active agents are wrapped in or adsorbed on the surface of nanoparticles in order to achieve safe and effective drug delivery and gene therapy [2,59]. Nanocarriers (including liposomes, micelles, niosomes, archaeosomes, dendrimers, ceramic, viral and metallic nanoparticles, and carbon nanotubes $[2,3,60,61]$ generally differ in size, composition, chemical stability, cell penetration ability and release properties. They also vary in terms of solubility and other characteristics of the agents they can hold. The proper choice of which system to be used depends on these factors along with the type of application they will contribute to [2].

When compared to traditional delivery systems, nanocarriers used in chemotherapy have higher therapeutic efficiency at low dosage and can accumulate preferentially in the desired locations due to the defective vascular architecture of most solid tumors. This enables the nanocarriers circulating in the blood to be entrapped inside the leaky vessels of the tumor, thus slowly releasing their contents, a process known as the enhanced permeability and retention effect (EPR). EPR allows drugs transported inside nanocarriers to remain in tumor tissues for extended periods, thus reducing the cytoxicity and unwanted side effects that may influence the function of other healthy organs such as the heart and kidneys [62-65].

Micellar drug delivery

What are micelles?

Micelles are colloidal dispersions that consist of hydrophilic tails and hydrophobic heads, the latter being composed of hydrocarbon chains. Due to their amphiphilicity, micelles have unique properties when dissolved in water [72,73]. Micelles can enclose hydrophobic drugs as well as imaging agents in their hydrophobic cores, and polymeric micelles can additionally transport drugs attached to the hydrophilic polymer of their corona $[8,9,74]$. Micelles can also be used to carry small organic molecules, peptides, carbohydrates, monoclonal antibodies, and DNA/RNA aptamers $[9,75]$.

When compared with liposomes, micelles are smaller in size, with a diameter ranging between $10-100 \mathrm{~nm}$ [22]. This size, although limiting the amount of drug delivered, allows for enhanced penetration into desired sites and organs, and increases the blood circulation time, since these nanocarriers are small enough to escape renal excretion [76].

The critical micellar concentration (CMC) is defined as the concentration at which micelles are formed [77]. Polymeric micelles are among the most widely studied DDS, and have a much lower CMC than micelles formed using low molecular weight surfactants [78].

Pluronic micelles are polymeric micelles composed of triblock copolymers of the hydrophilic poly(ethylene oxide) (PEO) and the hydrophobic poly(propylene oxide) (PPO). Hydrophobic drugs accumulate in their PPO hydrophobic core, while the PEO chains extend into the aqueous solution, preventing the adsorption of proteins on their surface and their subsequent recognition by the reticulo-endothelial system [8]. These micelles are able to sensitize multi-drug resistance (MDR) in cancer cells at low concentrations which explains 
4 S. E. Ahmed et al.

the increased attention they garnered in cancer treatment research in the past 20 years $[8,56,79,80]$.

Within the Pluronic type of micelles, P105 is the most widely researched for ultrasonic drug delivery $[8,55,56,81-$ 86]. The average molecular weight of P105 is 6500 , and this ABA-type triblock copolymer is composed of 37 PEO monomers (on both sides) and 56 PPO monomers in the middle [80]. The use of polymeric micelles to deliver chemotherapeutic agents in vivo is challenging, for two main reasons: their recognition by the immune system and their stability when diluted below their CMC (when injected into the blood stream, thus quickly dissolving and prematurely releasing the drug [41]. In order to make these micelles stable enough to reach the target site, the concentration of the polymer would have to be above the $\mathrm{CMC}$, and such concentrations may not be tolerated by the human body [80]. One way to overcome the first disadvantage (fast clearance) is to use "stealth micelles", which have their surface modified, usually by an exterior layer of PEO. The PEO layer prevents the fast clearance of the micelles once in blood circulation (the clearance due to their recognition by the cells of the reticuloendothelial system). The mechanism behind increasing the nanoparticle circulation time can be explained as follows: since PEO is a hydrophilic polymer, it associates with water molecules, and leads to the steric repulsion of proteins, thus preventing them from being adsorbed unto the micellar surface, avoiding their detection and subsequent clearance by different biological mechanisms (e.g. endocytosis, phagocytosis, liver uptake) [87]. Pluronic micelles have PEO inherently as part of their covalent structure and therefore solve this reticulo-endothelial system recognition problem. However, PEO molecules tend to block the entry of the micelles into the cells, where the drug is supposed to be released [88]. One way to overcome this is to use sheddable coatings that can be removed once the sterically stabilized micelles arrive at the target site, as reviewed by Romberg et al. [89].

The synthesis of a second generation of micellar drug carriers from P105 was undertaken in order to overcome the instability problem. These stabilized micelles, named NanoDeliv, were synthesized from P105 by copolymerizing an interpenetrating network (IPN) of thermally responsive acrylates in the hydrophobic micellar core, making these drug carriers more stable upon dilution [90], with an in vitro halflife of about $17 \mathrm{~h}$ [91]. The IPN expands at room temperature, which allows the accumulation of the drug in the hydrophobic core, and contracts above $31 \mathrm{C}$. This network is capable of trapping the drug molecules when these micelles are injected at body temperature. Upon injection the micellar solution is naturally diluted but the internal network prevents the degradation of the carrier's structure and keeps the drug encapsulated, minimizing its interaction with healthy cells and in the process reducing the well-documented side effects of conventional chemotherapy. This collapse at higher temperatures happens because with increase in temperature, there is a decrease in the association of water with the PEO
J Drug Target, Early Online: 1-33 blocks, causing the shrinking of these stabilized micelles [90]. NanoDeliv micelles have a size of about $60 \mathrm{~nm}$ at $37 \mathrm{C}$, a size that is still small enough to pass through cancer capillaries, and allow their extravasation at the tumor site, but large enough to avoid renal excretion [56]. NanoDeliv micelles release Dox upon exposure to US [91] but, for the same US intensity, these stabilized micelles release a lower percent of drug when compared with the non-stabilized P105 [92].

Finally, the group of Zeng and co-workers [93,94] developed a third generation of micellar drug carriers, with time-controlled degradation, which was shown to release Dox upon in vitro ultrasonication. These micelles were synthesized from the polymers PEO, N-isopropyl acrylamide (NIPAAm) and polylactate ester of hydroxyethyl methacrylate (HEMAlactate). The main advantage of this carrier is that its lifetime in systemic circulation can be controlled by choosing an appropriate composition of the polymeric blocks. Additional in vitro studies have also shown that the application of $70-\mathrm{kHz}$ US caused the release of Dox from the cores of these carriers [92].

\section{Micellar modifications and active drug targeting}

Nanocarriers can be modified in a number of ways to enhance their bio-distribution and uptake [11]. Micelles depend on passive targeting when no moiety is conjugated to their surface. Modifications of this type of micelles are made to increase their circulation half-life, their extravasation and penetration at the tumor site, and decrease the negative side effects by an appropriate selection of formulation parameters. The above-mentioned "stealth" micelles are one example of such modified DDS, and include di-block copolymers (such as poly(L-amino acid)-block -poly(ethylene oxide)) and triblock copolymers as mentioned above. Stealth micelles are mostly water-soluble and have higher molecular weights than normal micelles, and thus, higher structural stability [11].

A number of natural and synthesized surfactant molecules can be added to the micelles to increase the solubility of hydrophobic drugs in their core, depending on the solubilization capacity and the CMC. Such surfactants are categorized into: anionic (phosphates, carboxylates, sulfates, etc.), nonionic (ethoxylates, glucosides, etc.), cationic (usually aminecontaining surfactants) and zwitterionic surfactants (phosphocholines and synthetic surfactants) [10,95].

It is worth mentioning that the solubilization capacity and the $\mathrm{CMC}$ are greatly affected by the charge of the hydrophilic parts of the micelles and their chemistry, i.e. the solubilization capacity is maximum for non-ionic surfactants, minimum for anionic surfactants and in between for cationic and zwitterionic surfactants [10].

The second type of modifications is used to create micelles that are used in "active targeting", and conjugates sitedirecting moieties - ligands - to the surface of these nanocarriers [96]. Ligands such as antibodies, sugar residues, apoproteins and hormones, have the ability to recognize certain receptors overexpressed on the membrane of cancer cells and lead the nanocarrier to bind to the surface of the targeted cells. 
DOI: $10.3109 / 1061186$ X.2014.954119

This way, the therapeutic effects are significantly increased whereas the undesired side effects are reduced considerably [62,97].

The rate of drug release from micellar systems needs to be optimized, so as to obtain the maximum efficiency with fewer side effects: an early release will prevent the chemotherapeutic agent from reaching the target site, with less therapeutic effect, while a very slow release rate will prevent the drug from reaching the concentrations needed to obtain the desired effect. This led to the development of a third type of targeting (besides "passive" and "active"), namely "triggered targeting", [26]. In this approach, different stimuli are used to trigger the drug release, by changing certain internal conditions (e.g. temperature, pressure or $\mathrm{pH}$ ) or by applying an external field (including electric and magnetic fields, US, light or neutron beams) [54,95,97-100].

Another option to the site-specific drug delivery is to create "immunomicelles" by attaching antibodies or antibody fragments (the Fab fragment) to the micelles. It is first necessary to identify unique antigens overexpressed on the surface of a cancer cell, grow the specific monoclonal antibodies $(\mathrm{mAb})$ and finally attach the mAbs to the surface of the micelle [101]. Monoclonal antibodies are identical monospecific antibodies made by equally identical immune cells. In targeted cancer therapy, mAbs can be used when the tumor cell exhibits specific antigens to the antibodies $[102,103]$. Micelle-mAb conjugates are diblock copolymers that have an antibody attached to the surface, much like folated micelles are micelles conjugated with folic acid. Basically, monoclonal antibodies are chemically attached to reactive groups on the surface of polymeric micelles and can specifically interact with their antigens on the surface of the cancer cell. The first generation of these immunocarriers was synthesized using polyethylene glycolphosphatidylethanolamine (PEG-PE) conjugates. Experiments showed their increased accumulation at the tumor site when compared to non-targeted micelles. The mAbs used in cancer therapy are derived from the IgG isotype antibody, which consists of two antigen-binding fragments (Fabs) connected to a constant $(\mathrm{Fc})$ region. The molecule itself consists of two pairs of polypeptide chains folded into immunoglobulin domains. The variable region identifies and binds the antigens, while the constant region binds effector molecules of the immune system. The function of the antibody as a whole is to initiate an immunological response against an identified and targeted cancer cell. The mAbtarget/receptor must be overexpressed bytumor cells, but not healthy cells. It must be (i) easily identifiable by the antibody, (ii) stable in biological fluids, and (iii) overexpressed by all tumor cells to be treated [104-106].

Unfortunately, the majority of anti-cancer cell antibodies can recognize only specific tumors, but a notable exception is the monoclonal 2C5 antibody which possesses nucleosomerestricted specificity and is capable of recognizing a broad spectrum of tumors. mAb 2C5 is frequently conjugated to PEG-PE based micelles [103,106].
Release of chemotherapeutic drugs from micelles \& liposomes 5

Micelles decorated with 2C5 monoclonal antibodies have been shown to deliver a chemotherapeutic agent to both tumors in their early growth stages and fully developed mature tumors [106]. Another study speculated that this enhanced delivery is caused by the receptor-mediated endocytosis of these drugloaded immunomicelles [107].

\section{Micelles and ultrasound}

The Pluronic P105 micelles are ideal carriers for USactivated drug release, since low-frequency US (LFUS) has been shown to perturb their core, inducing the release of the encapsulated drug [55]. Also, the fact that the drug is quickly reencapsulated, when the US exposure is stopped, increases their feasibility as drug delivery vehicles [91]. Since these copolymeric micelles have been the most widely studied in ultrasonic/micellar drug delivery systems, the following subsections will mainly detail their use as triggered DDS.

Mechanisms of US-induced micellar drug release and cellular uptake

Drug release from micelles, induced by US, is triggered by the cavitational oscillations and subsequent collapse of gas

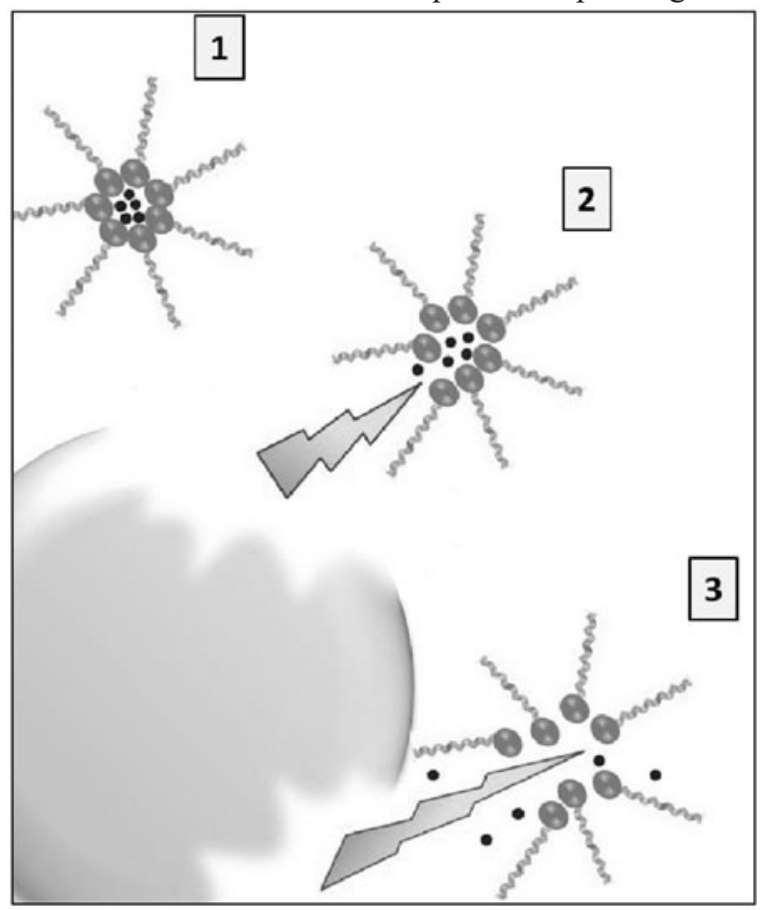

Figure 2. Drug release from micelles under ultrasound action. (1) An intact micelle. (2) Start of structural collapse of the micelle and initial release of the agent. (3) Collapse of the micelle and drug release due to the shockwave.

bubbles in an acoustic field (Figure 2). To achieve the desired drug release from polymeric micelles, an US threshold intensity that produces enough shear on the particles must be reached; below this threshold no release is observed $[92,108,109]$. Several US-related parameters must be efficiently controlled in the drug release process, including the 
6 S. E. Ahmed et al.

power density, sonication duration, frequency, position of the acoustic transducer, in addition to the polymer properties and the characteristics of gas bubbles formed during cavitation [110].

The process of ultrasonic-enhanced drug delivery from micelles has been explained by three different mechanisms: (i) US induces the drug release from the micelles outside of the cells and the drug enters the cells by a normal diffusion transport process; (ii) the application of US up-regulates endocytosis or pinocytosis (the process by which small volumes of extracellular fluid enter the cell via membrane invaginations and fuse with acidic lysosomes) of the drugcontaining micelles into the cells; (iii) US causes a perturbation in the cell membrane and this leads to the transport of the released or still micelle-encapsulated drug, into the cells.

Results obtained in in vitro and in vivo studies (sections "In vitro micellar drug release and modelling studies", "In vitro cellular studies", “In vivo studies using animal models') seem to exclude the first two proposed mechanisms as the sole or the primary mechanisms for US-enhanced drug uptake from micelles. These studies support a major role played by the third mechanism - the US-induced permeabilisation of the cellular membrane followed by transmembrane transport of free and micelleencapsulated drugs.

Table 1. In vitro studies using drugs encapsulated in micelles and ultrasound.

\begin{tabular}{|c|c|c|c|c|}
\hline Micelle type & Drug & US parameters & Overview & Reference \\
\hline Unstabilized P105 & Dox, $\mathrm{Rb}$ & $\begin{array}{l}20-90 \mathrm{kHz}, \mathrm{CW} \text { or } \\
\text { pulsed }\end{array}$ & $\begin{array}{l}\text { Drug release most efficient at } 20-\mathrm{kHz} \text { US and decreased } \\
\text { with increasing frequencies, even when the power } \\
\text { density was increased. Drug release higher at lower } \\
\text { P105 concentrations. Dox release higher than Rb } \\
\text { release (the latter inserts deeper at the core of the } \\
\text { micelle). Drug re-encapsulation observed between } \\
\text { pulses of US. }\end{array}$ & {$[55]$} \\
\hline Unstabilized P105 & Dox & $\begin{array}{l}20 \mathrm{kHz}, 0.058 \mathrm{~W} / \mathrm{cm}^{2} \text { Pulsed } \\
\quad \text { and CW }\end{array}$ & $\begin{array}{l}\text { Development of a kinetic model to be further developed } \\
\text { for the optimization of the insonation period } \\
\text { parameter. }\end{array}$ & {$[111]$} \\
\hline Unstabilized P105 & Dox & $20 \mathrm{kHz}, 70 \mathrm{kHz}$ & $\begin{array}{l}\text { Sensitivity analysis using ANN model, for the } \\
\text { optimization and control of Dox release. Design of a } \\
\text { model predictive controller. }\end{array}$ & {$[108,112]$} \\
\hline Stabilized and unstabilized P105 & Dox & $70 \mathrm{kHz}$ & $\begin{array}{l}\text { Higher release from unstabilized micelles than from the } \\
\text { stabilized ones (NanoDeliv). }\end{array}$ & e[92] \\
\hline Stabilized DSPE-PEG2000-Pluronic & Dox & $20 \mathrm{kHz}, 100 \mathrm{~W} / \mathrm{cm}^{2}$ & Release of $7-10 \%$ of the encapsulated drug & {$[113]$} \\
\hline PLA-b-PEG Copolymer & Nile Red & $1.1 \mathrm{MHz}$ & US irreversibly releases Nile Red from the micelles. & {$[114]$} \\
\hline PEO-b-PTHPMA Copolymer & Nile Red & 1.1.MHz & $\begin{array}{l}\text { US causes release from the micelles due to the hydrolysis } \\
\text { of the THPMA side groups. }\end{array}$ & {$[115]$} \\
\hline Unstabilized P105 & Dox & $\begin{array}{l}70 \mathrm{kHz}, 0.58,0.675 \text { and } \\
0.765 \mathrm{~W} / \mathrm{cm}^{2}\end{array}$ & $\begin{array}{l}\text { Model of release and re-encapsulation at three different } \\
\text { temperatures ( } 25 \mathrm{C}, 37 \mathrm{C} \text { and } 56 \mathrm{C}) \text { : (a) rate of micellar } \\
\text { destruction increases with temperature; (b) micelle re- } \\
\text { assembly decreases with temperature }\end{array}$ & {$[116]$} \\
\hline Stabilized and unstabilized & Dox & $70 \mathrm{kHz}$ & $\begin{array}{l}\text { Significantly lower rate of release from stabilized } \\
\text { micelles. No effect of temperature on the release and } \\
\text { re-encapsulation in unstabilized micelles. }\end{array}$ & {$[117]$} \\
\hline Unstabilized P105 & Dox & $\begin{array}{l}70 \mathrm{kHz},(0.1-0.8) \mathrm{W} / \mathrm{cm}^{2} \\
500 \mathrm{kHz}\end{array}$ & $\begin{array}{l}\text { Dynamic model of the oscillations of bubbles in the US field } \\
\text { at two different frequencies. Release observed } \\
\text { at } 70 \mathrm{kHz} \text { but not at } 500 \mathrm{kHz}\end{array}$ & $d[118,119]$ \\
\hline P105 with a folate moiety & Dox & $70 \mathrm{kHz}$ & $\begin{array}{l}\text { Folated micelles release more drug than non-folated ones. } \\
\text { Increase of release with power density, with maximum } \\
\text { of } 14 \% \text { at } 5.4 \mathrm{~W} / \mathrm{cm}^{2} \text {. No drug release below the } \\
0.55 \mathrm{~W} / \mathrm{cm}^{2} \text { threshold. Release follows a zero-order } \\
\text { model, re-encapsulation follows a first - order model. }\end{array}$ & {$[120,121]$} \\
\hline
\end{tabular}

In vitro micellar drug release and modelling studies

The studies presented in this section are summarized in Table 1. Husseini et al. [55] and Rapoport et al. [122] tested Dox release from Pluronic P105 micelles using both CW and pulsed US, with frequencies ranging between $20 \mathrm{kHz}$ and $3 \mathrm{MHz}$. They found that the efficiency of drug release decreased as the frequency increased due to the role of transient cavitation. An increase in power density also increased the amount of drug released when the US frequency was kept constant. Additionally, they reported that the use of pulsed US with longer pulses and shorter inter-pulses intervals allowed for a faster re-encapsulation between the pulses, which maintained a high concentration of the released drug, and hindered the undesired interactions between drug and healthy tissues.

The modeling of pulsed and continuous LFUS at $20 \mathrm{kHz}$ and $0.058 \mathrm{~W} / \mathrm{cm}^{2}$ applied for a total insonation period of $60 \mathrm{~s}$ was used in another study conducted by StevensonAbouelnasr et al. [111] The group proposed four mechanisms for the process of Dox release from Pluronic P105 micelles when triggered with US and its subsequent re-encapsulation. Those mechanisms are: (i) micellar destruction, (ii) cavitating nuclei destruction, (iii) micelles reassembly and, (iv) Dox reencapsulation. The study managed to develop a kinetic model that fits the 
DOI: 10.3109/1061186X.2014.954119

experimental data and suggested further investigations of this model in order to optimize insonation periods in future applications. As a complement to this work, and using 20- and $70-\mathrm{kHz}$ LFUS at various power densities, a sensitivity analysis was performed using an artificial neural network (ANN) model in an attempt to optimize and control Dox release from acoustically triggered unstabilized Pluronic P105 micelles [117]. ANN was also used to design a model predictive controller (MPC) that is capable of maintaining a constant release of the drug for a given period $[112,123]$. The release experiments were then extended by Husseini et al. [117] to include stabilized Pluronic P105 micelles and to study the effect of temperature on the unstabilized Pluronic P105 micelles. It was observed that the temperature did not have any effect on Dox release and reencapsulation time constants for unstabilized micelles. The release was higher for the unstabilized Pluronic micelles (when compared to the stabilized ones), possibly because the stabilization using an IPN appears to better preserve the integrity of the micellar structure when exposed to an external stimulus. Interestingly, there was no statistically significant difference between reencapsulation rate constants for stabilized and unstabilized micelles.

A dynamic model of the oscillations of a bubble exposed to $70-\mathrm{kHz}$ US with power densities in the range of $(0.1-0.8) \mathrm{W} /$ $\mathrm{cm}^{2}$ was also proposed and compared to a similar model at an ultrasonic frequency of $500 \mathrm{kHz}[124,125]$. The study concluded that release at $70 \mathrm{kHz}$ and $500 \mathrm{kHz}$ exhibit two different routes to chaos, which affected its behavior: Dox was released from polymeric micelles at LFUS (20 and $70 \mathrm{kHz})$ but the release was absent at $500 \mathrm{kHz}$. In another modeling study, the release and re-encapsulation of Dox under $70-\mathrm{kHz}$ US at three power densities $\left(0.580 \mathrm{~W} / \mathrm{cm}^{2}, 0.675 \mathrm{~W} / \mathrm{cm}^{2}\right.$ and $0.765 \mathrm{~W} / \mathrm{cm}^{2}$ ) and three temperatures (25C, 37C and 56C) were modelled and the kinetics and thermodynamic properties of drug release and micelle re-assembly and destruction were deduced [116]. It was shown that as the temperature increased, the rate of micellar destruction also increased, while that of micelle re-assembly decreased. More specifically, the study showed that the temperature dependence of the micellar destruction kinetics could be accurately represented using the Arrhenius equation.

The rate constant of Dox release also depends on the stabilization of the micelles. The in vitro release of Dox from several non-stabilized and stabilized carriers using 70-kHz US, was investigated [92] and the results showed a higher USinduced release of Dox from non-stabilized Pluronic micelles $(10 \%)$ than from its stabilized analog -NanoDeliv(3\%). Although these numbers seem low, one can argue that if $3 \%$ of drug is released each time US is applied, then the use of pulsed US could theoretically release the entire drug load in the presence of cells that compete for released Dox. Concerning release kinetics, it was recently shown that the drug release rates from stabilized micelles are significantly lower than those of non-stabilized ones [117]. The exposure to US seems to disturb the IPN of stabilized micelles, but the
Release of chemotherapeutic drugs from micelles \& liposomes 7 degradation time is long compared to the rate of release from the micelles; additionally, there were no significant differences between the network degradation rates after $1 \mathrm{~h}$ of exposure to 70- and 476-kHz US [126].

Ugarenko et al. [113] studied the release of Dox and formaldehyde-releasing prodrugs encapsulated in DSPEPEG2000 (1,2-distearoyl-sn-glycero-3phosphoethanolamineN-[amino(polyethylene glycol)-2000])Pluronic stable mixed micelles using LFUS at high-power densities $\left(20 \mathrm{kHz}, 100 \mathrm{~W} / \mathrm{cm}^{2}\right)$. The results showed that, upon micelle formation, no traces of the formaldehyde-releasing prodrugs were found within the micelles, while approximately $60 \%$ of Dox was encapsulated in their core. The group calculated an encapsulation retention half-life of approximately $12 \mathrm{~h}$ and reported that $7-10 \%$ of Dox was released upon US application. Their study concluded that the use of Pluronic in conjunction with US is an efficient DDS, and that formaldehyde-releasing prodrugs could potentially be administered separately, thus enhancing the formation of cytotoxic DNA adducts in tumor tissues.

More recently, Husseini and co-workers [121] reported on the combination of active targeting of polymeric micelles and the use of US as the release trigger. Using Pluronic P105 micelles with a folate moiety conjugated on the carriers' surface, they studied the relationship between the acoustic intensity and the kinetic constants of Dox release, using 70$\mathrm{kHz}$ LFUS. As is the case with non-targeted micelles, an increase in the release was observed as the power density increased, with a maximum release of $14 \%$ obtained at

$5.4 \mathrm{~W} / \mathrm{cm}^{2}$. Additionally, it was observed that no drug was released below a power density threshold of $0.55 \mathrm{~W} / \mathrm{cm}^{2}$, suggesting an important role of cavitation in the release process. To further evaluate whether this combination is an effective DDS in cancer therapy, in vitro studies using cell lines are currently being conducted. The kinetics of UStriggered release of Dox from P105 folated-micelles was deduced using mathematical models. The best fit to experimental data was found using a zero-order in release and firstorder in the re-encapsulation model.

All of the described studies used Pluronic compounds as micellar building blocks, but other types of polymeric micelles have also been studied. Zhang and co-workers [114] used HIFU to control the release of Nile Red from micelles composed of the block copolymer poly-lactic acid-bpolyethylene glycol (PLA-b-PEG), and proposed an irreversible mechanism triggered by transient cavitation at the HIFU focal spot. The same group [115] reported the synthesis of micelles of poly(ethylene oxide) and poly(2tetrahydropyranyl methacrylate) (PEO-b-PTHPMA) in aqueous solution, and their disruption using 1.1-MHz HIFU. They proposed that the hydrolysis reaction of THPMA at room temperature, resulting in the cleavage of the 2tetrahydropyranyl groups, was the mechanism behind this HIFU disruption. 


\section{In vitro cellular studies}

The studies described in the previous section confirmed the ability of US to release chemotherapeutic agents from polymeric micelles. This section will describe the effect and efficiency of US on micellar drug delivery in vitro (Table 2).

Loverock et al. [134] examined the effect of US on suspensions of single V79 Chinese hamster fibroblast cells and in spheroids formed from these cells; both were treated with adriamycin (ADM), an analogue of Dox [135]. It was found that the ADM performance was enhanced when US was applied and that this improvement was not due to the hyperthermic effects of US because similar levels of cell killing were reported when the temperature was raised from $37 \mathrm{C}$ to $40 \mathrm{C}$ at the same ADM concentration of $5 \mathrm{~mm}$.

Although this early research work did not use nanoparticles as DDS, it showed the effect of US on the enhanced chemotherapeutic performance of the free drug.
Munshi and co-workers [85] first reported the use of US in association with polymeric micelles to deliver antineoplastic drugs to cancer cells in vitro. Their study showed that a combination of $80-\mathrm{kHz}$ US and Pluronic P105-encapsulated Dox synergistically lowered the drug's $\mathrm{IC}_{50}$ from 2.35 to $0.19 \mathrm{mg} / \mathrm{ml}$.

Later, Pitt and co-workers [56,81,130,132] studied the differences between exposing Human Leukemia HL-60 cells to Dox in its free form, encapsulated in Pluronic micelles or encapsulated in NanoDeliv. The results showed that the cells exposed to free Dox were killed at a faster rate than those exposed to encapsulated Dox, regardless of using Pluronic or NanoDeliv micelles [81]. This situation was completely reversed when cells were exposed to $70-\mathrm{kHz}$ US: the encapsulated Dox was more effective in killing the cancer cells, than the free form of the drug. This indicated a synergism between Dox, micelles and US: in the absence of 


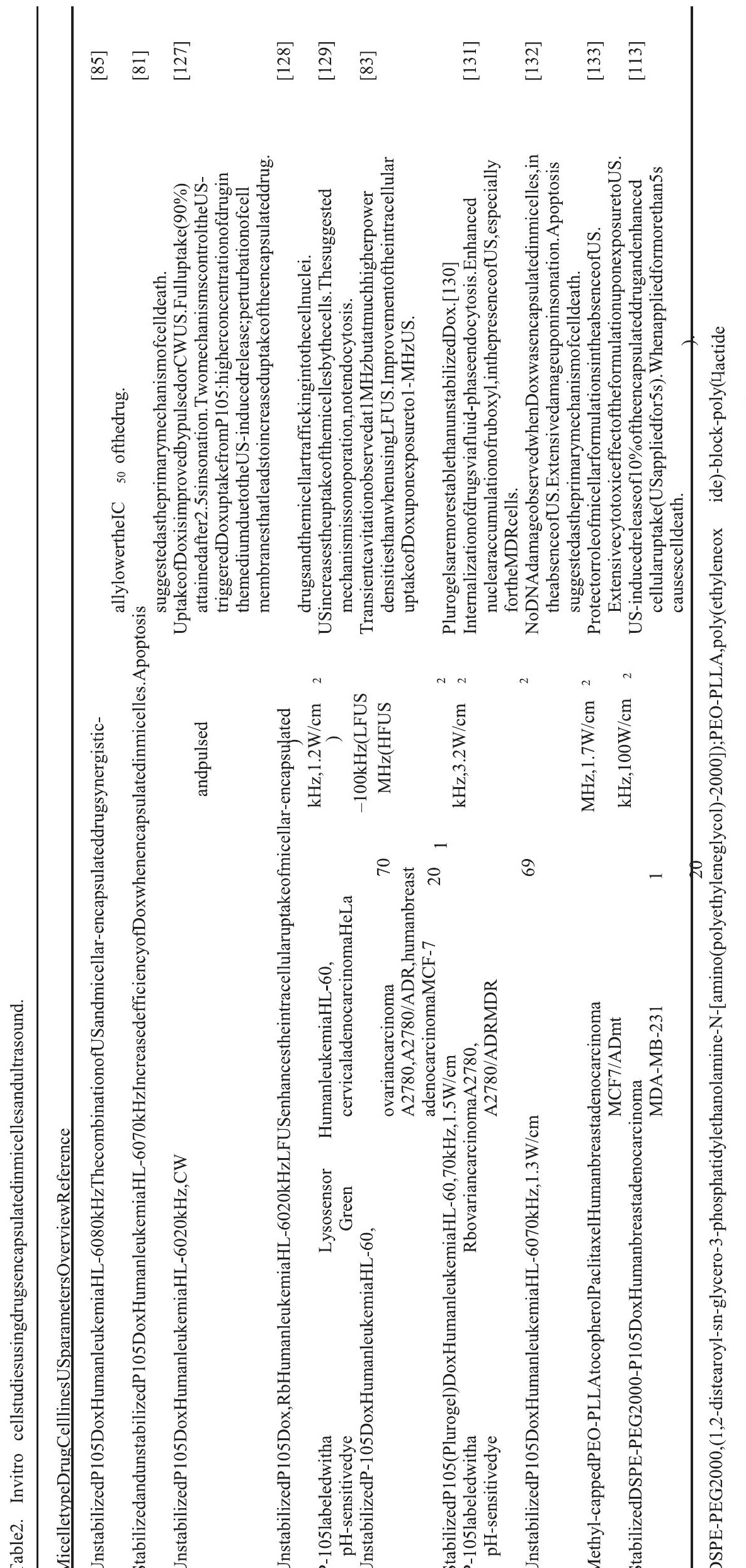


US the micelles protected the cells from the effects of Dox, but after US triggering, Dox was released and killed the cells at a higher rate than that caused by Dox alone. The cell damage observed in these studies $[81,132]$ was correlated to the amount of DNA damage, measured by the comet assay. These results indicate that apoptosis is the primary mechanism of cell death, because of the gradual DNA fragmentation, instead of the severe membrane and DNA damage seen in necrosis observed when US damages the cell membrane beyond repair.

After establishing that US induces the release of Dox and other drugs from micelles (see previous section) the groups of Pitt and Rapoport performed several studies to investigate if and how US enhances the uptake of drugs by cells, namely HL60 cancer cells [83,86,127-129]. One of the studies [127] reported improvements in drug uptake when LFUS $(20 \mathrm{kHz})$ was pulsed in tone bursts with durations ranging between 0.1 and $2.0 \mathrm{~s}$ and inter-pulse intervals with similar durations. The results showed that, at constant inter-bursts and a total US exposure time up to $3 \mathrm{~s}$, the uptake increased to a rate equal to the one observed when CW insonation was used (independent of the inter-pulse intervals length). This study also reported that the insonation time needed to reach $90 \%$ of full uptake was approximately $2.5 \mathrm{~s}$.

In another study by the same group [128], the mechanism of LFUS (20kHz)-induced uptake of Dox and ruboxyl by HL60 cells from fluorescently-labeled Pluronic micelles was investigated by spectrofluorimetry and fluorescence microscopy. The results showed that LFUS enhanced the intracellular uptake of Pluronic-encapsulated drugs. The authors proposed the combination of two mechanisms, presumably connected to acoustic cavitation, to explain the observed results: (i) LFUS enhances the drug release from micelles, and (ii) LFUS improves the uptake of micellarencapsulated drugs.

Later, the same group [83] studied the differences between Dox release and intracellular uptake from Pluronic micelles in promyelocytic leukemia (HL-60), ovarian carcinoma (A2780 and A2780/ADR) and breast cancer (MCF-7) cells, using LFUS $(20-100 \mathrm{kHz})$ and high frequency US (HFUS; 1MHz). They observed that the transient cavitation causing acoustic drug release from micelles started at much higher power densities when HFUS was applied in comparison with exposure to LFUS. The intracellular Dox uptake was improved upon exposure to HFUS even when this exposure lasted $15 \mathrm{~s}$ only.

Muniruzzaman and co-workers [84] studied the mechanism of the intracellular uptake of Pluronic P105 micelles and unimers, in the absence of US. To investigate the effect of the copolymer aggregation state, they used Pluronic P105 labeled with two fluorescein derivatives, and a proportional relationship between Pluronic uptake and micellar concentration was observed, as long as the concentration was kept below the CMC. They hypothesized that unimers are internalized via simple diffusion through the cell membrane while the internalization of Pluronic micelles inside the cells occurs via fluid-phase endocytosis.

In another study, Rapaport et al. [131] labeled Pluronic P105 micelles with a $\mathrm{pH}$-sensitive fluorescein derivative, which fluoresces with higher intensity at the neutral $\mathrm{pH}$ of the cytoplasm than at the endosomal acidic $\mathrm{pH}$, and studied their intracellular uptake and localization in A2780 drug-sensitive and A2780/ADR MDR ovarian carcinoma cells. Results showed that, above the $\mathrm{CMC}$, the endocytosis of Pluronic micelles and the subsequent permeabilization of the membranes of the endosomal vesicle by the Pluronic molecules, results in the transfer of Pluronic into the cytoplasm. For the MDR cells, this process occurred even below the $\mathrm{CMC}$, suggesting that the vesicles in drug-resistant cells are more sensitive to permeabilization by polymeric surfactants than drug-sensitive cells. Additionally the results showed that the nuclear accumulation of ruboxyl, a paramagnetic analog of Dox, was enhanced using Pluronic micelles and $69-\mathrm{kHz}$ US.

Husseini and co-workers [129] obtained different results in a study carried out to further investigate if the mechanism of US-induced drug uptake in HL-60 and HeLa cells involves endocytosis/pinocytosis. They used Pluronic P105 micelles labelled with the $\mathrm{pH}$-sensitive fluorescence probe Lysosensor Green, which fluoresces more intensively in acidic environments (e.g. the interior of endosomes). They observed that US $\left(70 \mathrm{kHz}, 1.2 \mathrm{~W} / \mathrm{cm}^{2}\right)$ increases the uptake of the probelabelled micelles by HL-60 or HeLa cells, but does not increase the amount of the probe present in endosomes, which invalidated the hypothesis that the US-induced uptake mechanism is related to endocytosis. Rather, the study hypothesized that sonoporation is probably the main mechanism responsible for this enhanced cellular uptake.

The results obtained in the previously described studies indicate that US enhances the intracellular uptake of drugs from polymeric micelles, due to the US-triggered drug release from the micelles and also due to an enhanced uptake of micellar-encapsulated drug. Additionally, the described results refuted another hypothesis: US triggers the drug release from micelles outside the cells, and this is followed by the simple diffusion of the drug into the cells. However, these results could not clarify if the P105 micelles (with or without drug) entered the cells through pores in the membrane or via endocytosis. Several more studies were performed in an attempt to answer this question. Taken together, they emphasize the effect of the stresses produced by the ultrasonic cavitation on the cell membrane as playing an important role in improving drug release and uptake by creating transient 
holes (sonoporation) in their membrane. Generally, these disruptions are repairable, and hence non-lethal.

Several studies by the group of Tachibana [136-143] provided direct evidence of the US-induced increase in cell membrane permeability and skin porosity. As an example, in an early study by this group [139], HL-60 cells growing in suspension were exposed to $255 \mathrm{kHz}$ of continuous US at a power density of $0.4 \mathrm{~W} / \mathrm{cm}^{2}$, with merocyanine 540 (MC 540) as a drug/tracer for a duration of 30 s. Usinga scanning electron microscope, the authors observed the changes that occurred on the cell surface when sonicated, and found that the death of tumor cells was caused by the quick development of pores in the cell membrane. The same group [140] studied the cytotoxic effects of cytosine arabinoside in HL-60 cells upon exposure to low intensity $\left(0.3 \mathrm{~W} / \mathrm{cm}^{2}\right) 48-\mathrm{kHz}$ US, and observed an increase in cell death upon insonation. In control samples exposed to US alone for 120 s, no statistically significant differences were observed when compared to non-treated control cells. The insonated cells were visualized by scanning electron microscopy, revealing a slightly disrupted cell membrane as well as a decrease in the microvilli numbers. The authors suggested that low intensity US increased drug uptake by HL-60 cells, by disturbing and modifying the cell membrane. Likewise, a study performed by Saito et al. [144] using corneal endothelium cells, showed a reversible increase in the membrane permeability upon exposure to US, with the membranes regaining their integrity after several minutes.

Prentice and co-workers [145] reported similar results using MCF7 cells exposed to continuous 1-MHz US at high power densities. The micrographs obtained by atomic force microscopy indicated that single cavitation events were responsible for causing holes in the cell membrane, and the authors hypothesized that sonoporation occurs through a synergistic interplay with multiple processes being involved.

Stringham and co-workers [146,147] also observed the US induced disruption of cellular membranes in studies using the model drug calcein, and emphasized the role of collapse cavitation in this process. They used an in vitro model of rat colon cancer (DHD/K12 TRb cells) in order to test the hypothesis that cavitation and the permeability of the cell membrane were linked. They observed that free calcein, which usually does not penetrate the cell membrane, accumulated inside the cells upon exposure to pulsed $476 \mathrm{kHz}$ US, at power densities in the range of $2.75-5.5 \mathrm{~W} / \mathrm{cm}^{2}$. This accumulation decreased when the pressure was increased to $3 \mathrm{~atm}$, which supports the hypothesis that inertial cavitation is directly related to the cellular drug uptake. This increase in pressure, at a constant US intensity, decreases the cavitational activity, thus reducing the shear stress on both micelles and cells [148,149]. Furthermore, a linear proportionality was reported between membrane permeability and both the power density and the duration of insonation. Similar results were reported when applying 1-MHz of pulsed-US for a duration of $5 \mathrm{~s}$ to bovine endothelial cells [32].

The studies by Schlicher and co-workers [150,151] have also provided evidence that US reversibly increases plasma membrane permeability. Data obtained by flow cytometry coupled with electron and fluorescence microscopy showed that US causes repairable disruptions in the cell membrane, via cavitation events [149]. In a later study [150], DU145 prostatecancer cells were exposed to 20 pulses of $24-\mathrm{kHz}$ LFUS at a pulse length of $0.1 \mathrm{~s}$ and pressures of $0.36,0.54$ and $0.71 \mathrm{~atm}$, in order to examine the morphological changes occurring in the cells after sonication, and to further investigate the nature of the sonoporation phenomenon. The study hypothesized that sonoporation (which directly affects intracellular uptake) could be caused by the exposure to acoustic cavitation the same way poration occurs due to exposure to other mechanical stimuli. The study also suggested that the changes in the cell membrane depended on the degree of sonoporation, and further hypothesized that the same findings would be valid if HFUS was applied. Zhou et al. [152] managed to measure the pore size generated in sonoporation and to report similar findings using the voltage clamp technique and Xenopus laevis oocytes as a model system, with 1.075-MHz US applied with pulses of $0.2 \mathrm{~s}$ at an acoustic pressure of $0.3 \mathrm{MPa}$.

However, other recent studies support the hypothesis of the up-regulation of endocytosis. Meijering et al. [153] observed this effect in endothelial cells in a study that used micro bubble targeted delivery, while Hauser et al. [154] reported an enhancement of the endocytic activity in human fibroblasts exposed to US, with no observed structural membrane damage.

Since different studies report different results, the mechanism of drug uptake induced by US is still unresolved. These obtained conflicting results suggest that different cells respond differently to the US stimulus, hence a general conclusion cannot be derived.

Although Pluronic P105 is the most widely studied polymeric micellar system for US-assisted drug delivery, several other systems have been studied in vitro. For example, Howard and co-workers [133] synthesized micelles of methylcapped poly(ethylene oxide)-co-poly-(L-lactide)tocopherol with encapsulated Paclitaxel and studied how the application of US $\left(1 \mathrm{MHz}, 1.7 \mathrm{~W} / \mathrm{cm}^{2}\right.$ power density and a duty cycle of $33 \%$ ) altered the effect of the drug on a breast cancer drug resistant cell line, MCF7/ADmt. The results emphasized the importance of using polymeric micelles to protect the cells from the side effects of the drugs, since in the absence of US, it was observed that less encapsulated Paclitaxel accumulated inside the cells, when compared to the free drug. However, upon exposure to US, the accumulation of encapsulated 
Paclitaxel dramatically increased, confirming the effectiveness of US as a trigger for drug release at targeted tissues.

The group of Ugarenko [113] used Dox encapsulated in P105 micelles stabilized with disteroylphosphoethanolaminePEG200, instead of an IPN. The encapsulation of Dox in these mixed micelles reduced Dox uptake by MDA-MB-231 breast cancer cells in vitro, while the application of US $\left(20-\mathrm{kHz}\right.$ at $100 \mathrm{~W} / \mathrm{cm}^{2}$ for $\left.5 \mathrm{~s}\right)$ released about $10 \%$ of the Dox from the micelles and increased cellular uptake. However, it was also observed that the use of US, at this high-power density, for longer than a $5 \mathrm{~s}$ period caused the death of the HL-60 cells.

Chen and co-workers [155] developed a new polymeric P105/F127 mixed micelle to encapsulate the poorly soluble anti-tumor drug docetaxel (DTX), and studied the effect of this system on Taxol-resistant non-small cell lung cancer (human lung adenocarcinoma cell line A549/Taxol). The results obtained showed that the encapsulated DTX had a higher hypersensitizing effect in the A549/Taxol cell lines than the free drug.
The above-mentioned in vitro studies provide evidence that the use of US induces cavitation processes which in turn produce stresses on the cell membrane, allowing for an increase in drug uptake. There appears to be an in vitro synergistic effect between chemotherapy and US: the application of US both releases drug from nanocarriers and creates transient, repairable holes in the cell membrane, through which released molecules or even micelles, can enter the cytosol, possibly bypassing the endocytotic pathway.

In vivo studies using animal models

Either rat or mouse models have been used in all the in vivo research that investigated tumor progression when treated with ultrasonically-triggered micellar-encapsulated drugs (Table 3).

One of the first in vivo studies, performed by Nelson and co-workers $[156,157]$ used a rat model to study the effect of 


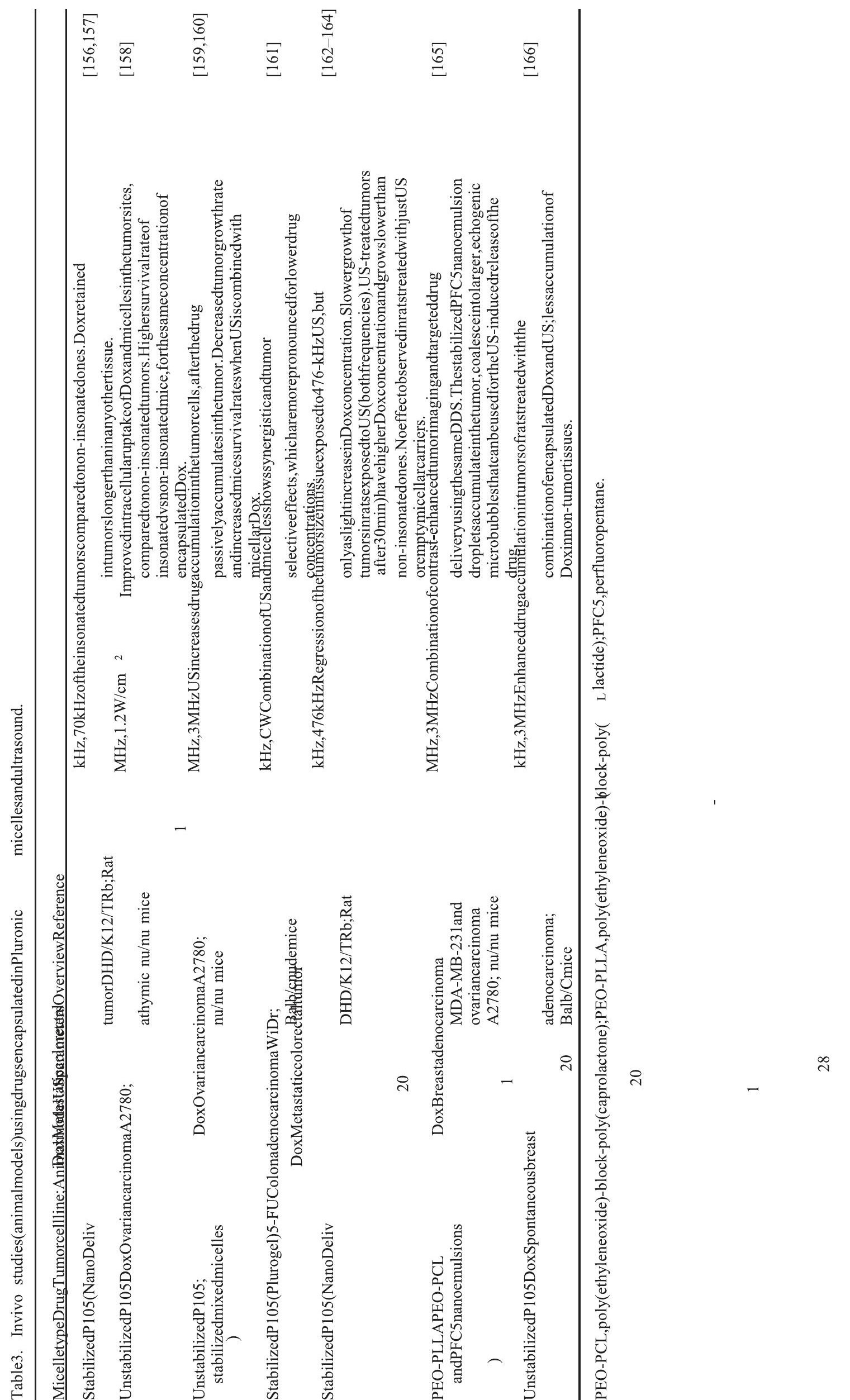


14 S. E. Ahmed et al.

Dox and US on a colon carcinoma (DHD/K12/TRb cells), namely investigating the effect of different applied US power densities, frequencies, Dox concentration, power train (CW or pulsed), and treatment regimens (once or twice weekly, for a total of 4 weeks). Tumors were inoculated in each of the rat hind legs, and Dox (free or encapsulated in Nano Deliv micelles) was administered systematically, thus both tumors obtained equal concentrations, but only one of the leg was exposed to a 1-hour US treatment. The results showed that the higher concentrations of Dox $(4-8 \mathrm{mg} / \mathrm{kg})$ were lethal, while concentrations of 1.33 and $2.67 \mathrm{mg} / \mathrm{kg}$ were not [157]. It was also observed that the size of the insonated tumors were significantly smaller than that of non-insonated ones, for all the tested concentrations of encapsulated Dox. Furthermore, a significant decrease in size of the subcutaneous tumors was observed for the rats receiving $2.67 \mathrm{mg} / \mathrm{kg}$ of NanoDelivencapsulated Dox, when the tumors were exposed to $20-\mathrm{kHz}$ and $70-\mathrm{kHz}$ US for $1 \mathrm{~h}$ [157]. The drug was retained in tumors longer and in higher concentrations than in any other tissue, a result that suggests a drug accumulation by the EPR effect with a maximum concentration observed at $12 \mathrm{~h}$ [164].

Staples and co-workers performed several in vivo studies using the same $\mathrm{DHD} / \mathrm{K} 12 / \mathrm{TRb}$ colorectal epithelial tumor bearing rat model, obtaining results that support the main role of the cell membrane perturbation in the process of drug uptake by cells $[162,163,167]$. The results showed a significantly slower growth of tumors in a rat model treated with NanoDeliv-encapsulated Dox and exposed to $20-\mathrm{kHz}$ and 476$\mathrm{kHz}$ US $15 \mathrm{~min}$ per week [163]. Their study found a regression of the tumor size in the 476-kHz US-exposed tissue, even if the concentration of Dox in the tumor tissue was only slightly increased [162]. This result could not be explained by simple Dox release, and the authors hypothesized that possibly the cell membranes were being stressed in vivo, similar to that observed in vitro. Additionally, no statistically significant difference was observed between the tumor volumes treated with the Dox micellar systems and 20- and 476-kHz US (at the same mechanical index and time-averaged power density), a result that the authors attribute to the noise and scatter in the data set [163]. The results obtained in these studies suggest an important role for US-induced cavitation events on the drug release from the NanoDeliv micelles, and on the increased permeability of the cells and capillary walls. The same group $[162,164]$ determined the time course concentration of Dox in tumor tissue and its distribution in other organs, after the rats were injected with Dox-NanoDeliv and the tumors were exposed to the same frequencies of US employed in the above study. The results showed that after $30 \mathrm{~min}$ post-injection, the UStreated tumors had a higher Dox concentration and a slower growth than the non-insonated controls. However, $6 \mathrm{~h}$ postinjection no significant difference was observed between the Dox concentrations in insonated and control tumors. The insonation frequencies 20 and $476 \mathrm{kHz}$ - did not affect the tumor concentration of Dox or the tumor growth rates, which is in accordance with the results obtained in their previous study [163]. The concentration of NanoDeliv- encapsulated
J Drug Target, Early Online: 1-33

Dox in the heart, kidneys, liver and muscle tissues, showed a temporal exponential decay, and the encapsulated drug was undetectable after 1 week, while very low levels could still be measured in the tumors. Multiple weekly administrations of this formulation over a course of 4 weeks caused a significant accumulation of the drug in the heart, but not in the liver, skeletal leg muscle, or tumors. Controls were performed by treating the tumors with US alone or using empty NanoDeliv micelles and it was observed that these did not have any effect on the tumor growth or the lifespan of the rats [164].

Similar results were obtained when mouse models were used. Rapoport et al. [158] applied 1-MHz US to immune compromised athymic nu/nu mice bearing ovarian carcinoma tumors after being treated with Dox encapsulated in Pluronic P105 micelles. The group confirmed the presence of the EPR effect when micelles were used as drug carriers (even before exposure to US). When US was applied, they reported a significant improvement in the intracellular uptake of Dox and micelles in the tumor sites when compared to mice that were not insonated. A decrease in drug uptake by the heart and kidney tissues was also reported while an enhanced uptake by the tumor, liver and spleen was measured after several hours post-treatment. The group also observed a higher survival rate of insonated mice when compared to noninsonated mice treated with the same concentration of encapsulated Dox.

The same group [165] showed an increased drug extravasation upon US application. $\mathrm{Nu} /$ nu mice implanted with breast (MDA MB231 cells) and ovarian (A2780 cells) cancers were treated with Dox encapsulated in polymeric micelles, and exposed to $1-\mathrm{MHz}$ or $3-\mathrm{MHz}$ US. The cavitation activity was monitored using fluorescence techniques. The results showed that Dox was released due to the oscillation and collapse of microbubbles and that Dox uptake by cancerous cells was significantly increased upon exposure to US. Furthermore, drug accumulation in other organs was negligible indicating that this sonicated-micellar DDS was tumor-selective.

Myhr and Moan [161] who conducted a study using both Plurogel micelles and PEGylated liposomes (section " In vivo studies using animal models and clinical trials"'), used $20-\mathrm{kHz}$ US to sonicate a human colon cell line (WiDr) inoculated in a group of $144 \mathrm{Balb} / \mathrm{c}$ nude mice, after injecting Plurogelencapsulated fluorouracil (5-FU) at two different concentrations (100 and $200 \mathrm{mg} / \mathrm{kg})$. Their experiments showed synergistic and tumor selective effects when the combination of US and micelles was used, and that these effects became more pronounced as the drug concentration was lowered.

Howard et al. [133] also studied the in vivo effects of using Paclitaxel encapsulated in micelles of methyl-capped poly(ethylene oxide)-co-poly-(L-lactide)-tocopherol, in a $\mathrm{nu} / \mathrm{nu}$ mice inoculated with a breast cancer drug resistant cell line. The results showed that the use of the encapsulated drug in conjunction with US led to a complete tumor regression, similarly to what had been observed in in vitro studies.

Another important in vivo study was performed by Hasanzadeh et al. [166] on adult female Balb/C mice 
DOI: 10.3109/1061186X.2014.954119

inoculated with spontaneous breast adenocarcinoma tumors. The mice were divided into three groups: one treated with a $1.3 \mathrm{mg} / \mathrm{kg}$ dose of Dox, the second treated with the same dose of Dox but encapsulated in Pluronic P105 micelles, and the third treated with the same concentration of encapsulated Dox in the presence of $28-\mathrm{kHz}$ and $3-\mathrm{MHz}$ US. The third group showed enhanced drug accumulation in tumor tissue (8.69 times and 2.60 times more drug accumulation than that observed in the first and second treatment groups, respectively). Also, the group receiving US showed less accumulation of Dox in other tissues and organs. This accumulation was 3.35 and 2.48 times less than the first and second groups, respectively, which led to a measurable decrease in the side effects of free Dox administration.

Besides studying the in vitro effects of DTX-loaded P105/ F127 mixed micelles, Chen and co-workers [155] also reported their in vivo action in rat and mice models. Their pharmacokinetic study showed that the micellar system was able to circulate for a longer time and induced higher tumor inhibition rates than the free drug.

So far, there are no FDA approved micellar systems for use against cancer. Thus, we can expect more researchers to direct their attentions towards optimizing a micelle-carrier system that can be utilized in clinics. Liposomes, on the other hand, have been FDA approved for cancer treatment since 1995. The next section introduces the structures and functions of liposomes and summarizes the studies where US was used as a trigger mechanism to release chemotherapeutic agents from liposomes and enhance the drug's cellular uptake.

\section{Liposomal drug delivery}

What are liposomes?

Liposomes are small spherical vesicles composed of a lipid bilayer enclosing an aqueous compartment. Similar to the cellular membrane, the liposomal lipid bilayer is mainly composed of phospholipids with polar hydrophilic heads attached to long, non-polar, hydrophobic tails (Figure 3), and also containing other molecules such as cholesterol, carbohydrates and proteins [168]. Several bioactive agents, such as drugs, peptides, vaccines, plasmid DNA, antisense oligonucleotides or ribozymes, cosmetics and nutraceuticals, can be encapsulated inside liposomes [5].

Liposomal structures vary in size, with the smallest being about $20 \mathrm{~nm}$ in diameter and the largest reaching up to $1 \mathrm{~mm}$ or greater. Liposomes can be classified according to their size and the number of lipid bilayers they possess. Liposomes that have more than one fluid compartment separated by multiple lipid bilayers are called multilamellar vesicles (MLVs), while liposomes that have a single fluid core with a diameter of $0.05-$ $0.25 \mathrm{~mm}$ are designated as unilamellar vesicles (ULVs). The ULVs can be further divided into small unilamellar vesicles (SUVs) with a diameter of $0.05-0.10 \mathrm{~mm}$, and large unilamellar vesicles (LUVs) having a diameter of 0.05$0.25 \mathrm{~mm}$ [169]. This classification is illustrated in Figure 4 [170].
Release of chemotherapeutic drugs from micelles \& liposomes 15

Encapsulation of drugs in liposomes depends on the drug solubility: while water-soluble drugs are carried in the internal hydrophilic aqueous core, lipid-soluble ones are carried in the hydrophobic membrane, and peptides and small proteins are carried in the lipid-aqueous interface. Therefore, the solute itself is either contained in the aqueous compartment if it is a polar solute, or in the lipid bilayers if it is lipophilic or amphiphilic. The ULVs are the most adequate liposomal groups for use in chemotherapy because the size of

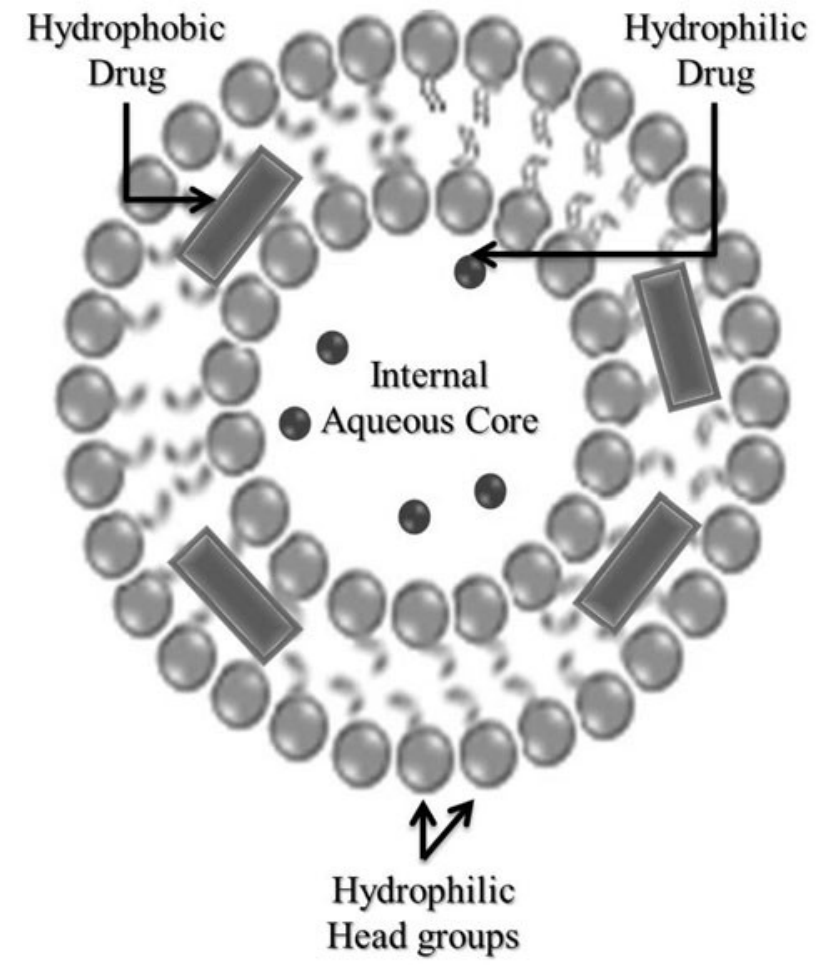

Figure 3. Schematic depicting the structure of liposomes (adapted from [76]). Liposomes are constituted of one or more lipid bilayers surrounding aqueous cavities that encapsulate hydrophilic drugs. Additionally, hydrophobic drugs can be carried within the lipid bilayer.

their inner aqueous compartment is small compared to their whole structure, allowing them to transport higher concentrations of the desired anti-neoplastic agents [169].

\section{Liposome modifications and drug targeting}

Liposomes, like micelles, can also be tailored to fit their intended function, through careful control of certain parameters [171]. These parameters include lipid components, particle size [172,173], cholesterol content [174], surface charge [175], lipid membrane fluidity [176] and steric stabilization [177,178].

"Stealth' liposomes, sterically-stabilized liposomes, have a prolonged half-life in blood circulation as a result of attaching hydrophilic polymers (e.g. PEG-poly ethylene glycol) to their surface, which avoids protein adsorption and hence reduces opsonization $[97,179,180]$. PEG creates a steric barrier that delays the mononuclear phagocyte system (MPS) from recognizing these liposomes and thus clearing them from 
$16 \mathrm{~S}$. E. Ahmed et al.

the blood stream [5]. PEGylated liposomes also have the ability to cross in vivo biological barriers and can be used to treat solid tumors, which explains their numerous applications in the area of cancer chemotherapy [181,182].

Similar to micelles, liposomes can be actively modified or "actively targeted" when ligands are conjugated to their surface. A widely used type of actively targeted liposomes is the group of immunoliposomes, whose surface is conjugated to specific antibodies or antibody fragments, enhancing their binding properties to targeted receptors. Cancer-specific immunoliposomal targeting is a major area of research in drug delivery [183,184].

Figure 4. Liposomes of different sizes and number of lamellae (adapted from [170]). MLVs, multilamellar vesicles; ULVs, unilamellar vesicles; SUVs, small unilamellar vesicles; LUVs, large unilamellar vesicles. The numbers indicate the diameter range for each of these categories.
J Drug Target, Early Online: 1-33

Recently, a new type of echogenic liposomes, developed by the research group of Pitt at Brigham Young University [187,189-191], was described. These liposomes, called eLiposomes, contain a liquid emulsion of perfluorocarbons (PFC), and the authors suggest that US can break open the eLiposomes by decreasing the local pressure below the vapor pressure of the PFC emulsion, thus allowing it to boil to a gas phase. Advantages of the eLiposomes include the fact that they are small enough to extravasate in tumors and are responsive to low-intensity US. Recently, Lin and Pitt [192] reviewed the acoustic droplet vaporization phenomenon, with emphasis on how it relates to drug release from carriers using HIFU.

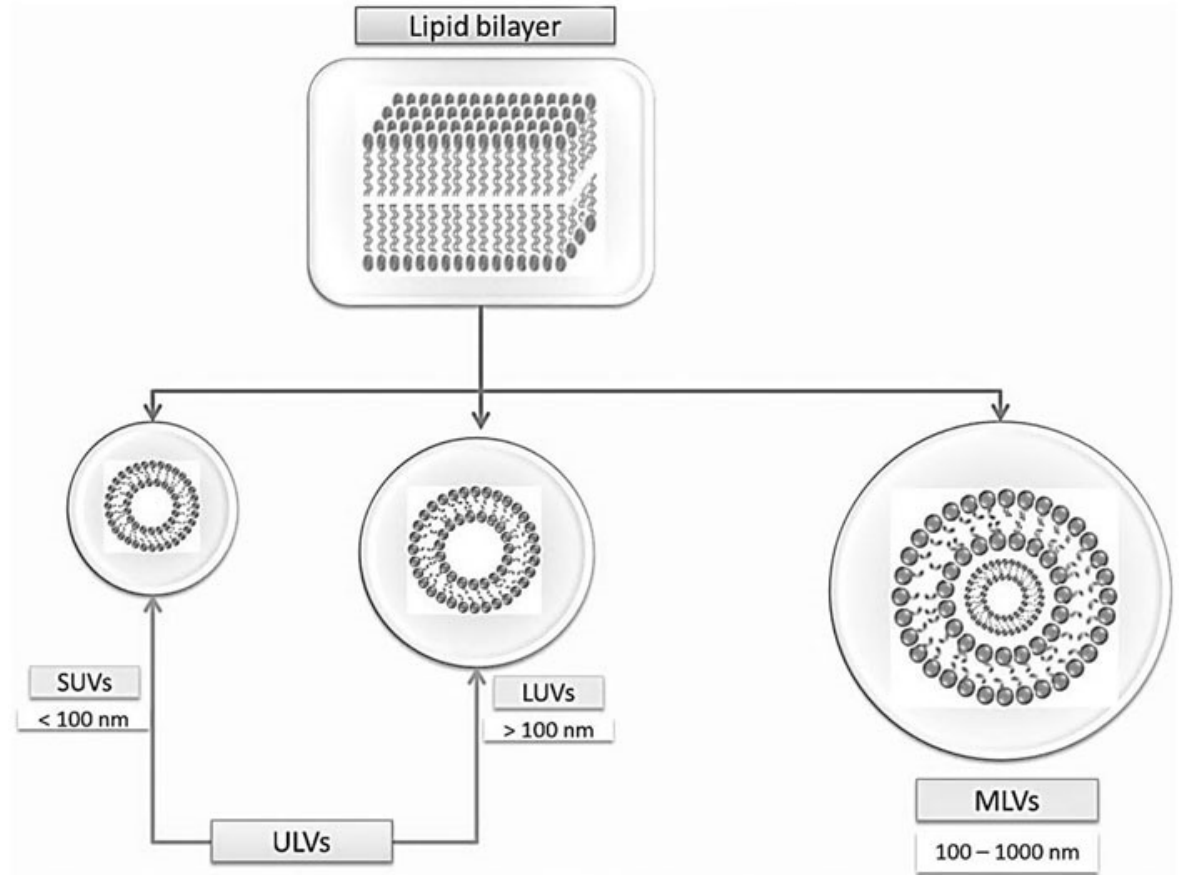

Liposomes, like micelles, can also be "remotely triggered", using the same stimuli mentioned in the previous section "Micellar modifications and active drug targeting". In the next section, we will summarize the results of using liposomes in conjunction with US to release and deliver chemotherapeutics to cancer tissue.

\section{Liposomes and ultrasound}

Ultrasound can induce either thermal or non-thermal effects in liposomes, and these DDS can be designed in order to respond to an increase in temperature, mechanical effects, or both [31]. Drug release induced by low-frequency US is mainly associated with mechanical effects such as transient cavitation, while high-frequency US is mainly associated with thermal effects.

Liposomes usually do not contain gas, hence they are not particularly sensitive to US. However, they can be designed to have echogenic properties either by using specific preparation methods (e.g. freeze-drying) or by incorporating nanoemulsions into their inner compartments [6,185-188]. These acoustically-active liposomes (AAL), also called echogenic or bubble liposomes, contain a gas phase or an emulsion that can vaporize, which makes them responsive to US, and hence can be used as a DDS [189].
Nevertheless, more research in the area of PFCs is needed in order to improve their design and tune the parameters that affect their performance as activatable agents [193].

US-induced hyperthermia can also be used as a strategy to release drugs when they are encapsulated in temperaturesensitive liposomes [194]. The lipid bilayer of most liposomes can transition from a solid-ordered (SO) phase to a liquiddisordered (LD) phase, and vice-versa, and this transition occurs at a temperature which is dependent on the molecular structure of the phospholipids present in the bilayer [31]. An intermediate liquid ordered (LO) phase can also occur if cholesterol, or other membrane-active sterol, is present in the bilayer [195]. Liposomes undergoing phase transitions are more permeable than in any other phase due to defects in the bilayer packing. Similarly, liposomes in the LD phase are more permeable than in the LO and SO phases [196]. This temperature-dependent phase transition was used to explore the concept of thermal control of drug delivery using temperature-sensitive liposomes (TSL), as first reported by Yatvin and co-workers [197]. Hence, the lipid composition of the liposomes determines their temperature-related behavior, and hence their permeability, which is directly related to the drug-loading stability and drug-release rate [198]. In the next 
DOI: 10.3109/1061186X.2014.954119

sections, the in vitro and in vivo work conducted using liposomal DDS in conjunction with US, is reviewed.

In vitro liposomal drug release and modelling studies

The studies presented in this section are summarized in Table 4. The research group of Barenholz [199] studied the efficiency of LFUS $(20 \mathrm{kHz})$ and HFUS (1 and 3MHz)triggered release of Dox from PEGylated liposomes (a drug commercialized under the names Doxil/Caelyx/ LipoDox). They observed that, after
Release of chemotherapeutic drugs from micelles \& liposomes 17 30 min of exposure to LFUS, $85 \%$ of Dox was released in saline solution, while $61 \%$

was released in human plasma. These percentages sharply decreased to $58 \%$ and 5\%, respectively, when 1-MHz HFUS was used. A further decrease in release occurred when $3-\mathrm{MHz}$ US was applied. These differences in the rate and amount of release, as the frequency increased, were hypothesized to occur due to cavitation; while the differences between the release in saline and human-plasma can be explained by the fact that plasma proteins absorb some of the acoustic energy, thus reducing the number of cavitation events. 


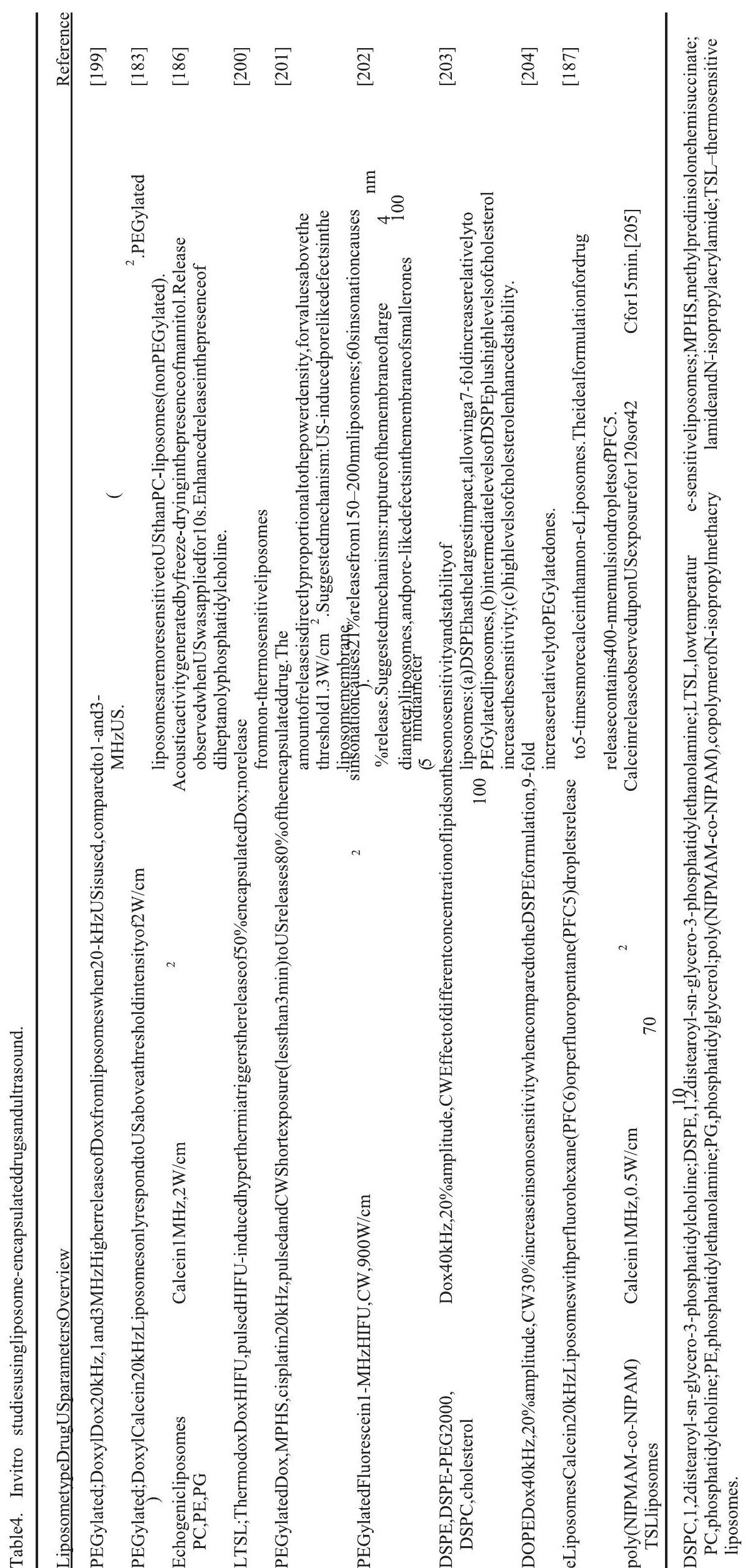


DOI: 10.3109/1061186X.2014.954119

Lin and Thomas [183] performed calcein release studies to access the susceptibility of PEGylated liposomes to LFUS $(20 \mathrm{kHz})$. They observed that these liposomes, similar to the control phosphatidylcholine (PC) liposomes, did not respond to US below a threshold intensity of $2 \mathrm{~W} / \mathrm{cm}^{2}$. However, above this threshold, the PEGylated liposomes were 10-fold more sensitive to US, showing a higher permeabilisation of the liposomal membrane. The researchers concluded that PEGlipids and other similar lipids significantly enhance the ability of LFUS to permeabilise 100nm unilamellar liposomes, possibly due to the formation of pores in the liposomal membrane (nanoporation), membrane destabilization, or both.

Similar results were obtained by Chen and $\mathrm{Wu}$ [202] using HIFU of $1 \mathrm{MHz}(\mathrm{CW})$ and $900 \mathrm{~W} / \mathrm{cm}^{2}$. They observed the release of approximately $21 \%$ of the encapsulated fluorescent agent fluorescein from 150-200nm liposomes, when US was applied for a mere $10 \mathrm{~s}$, whereas the percentage release increased to $70 \%$ when sonicating for $60 \mathrm{~s}$. The group suggested that inertial cavitation induced by HIFU led to the rupture of the membrane of large (4100nm diameter) liposomes, while it created pore-like defects in the membrane of smaller (5100nm diameter) ones.

Huang et al. [186] observed the release of calcein from echogenic liposomes composed of PC, phosphatidylethanolamine, phosphatidylglycerol, by applying $1-\mathrm{MHz} \mathrm{US}$, at a power density of $2 \mathrm{~W} / \mathrm{cm}^{2}$, for $10 \mathrm{~s}$. The liposomes were prepared by freeze-drying in the presence of mannitol, which was essential for improving the encapsulation efficiency (15\% under these conditions). Furthermore, the results have also shown that the inclusion of diheptanolyphosphatidylcholine in the liposomes increased their sensitivity to US, leading to a more efficient drug release.

Dromi and co-workers [200] studied pulsed- HIFU as a source of hyperthermia to trigger the release of Dox from low temperature sensitive liposomes (LTSL; ThermoDox; Celsion Corp.). The in vitro results showed that the HIFU-induced hyperthermia caused the release of $50 \%$ of the Dox encapsulated in LTSL, but did not cause drug release from non-thermosensitive liposomes (e.g. Doxil).

Schroeder and co-workers [201] studied the effect of $20 \mathrm{kHz}$ LFUS on the release rates of three different drugs (i.e. Dox, methylpredinisolone hemisuccinate, and cisplatin) encapsulated in PEGylated liposomes. It was observed that, for all 3 formulations, a short exposure (53min) to both pulsed or CW US released nearly $80 \%$ of the encapsulated drug. A linear relationship between LFUS power density and the amount of drug release was also reported. An intensity threshold of about $1.3 \mathrm{~W} / \mathrm{cm}^{2}$ was recorded and an increase in release percentage and rate was observed above this threshold, supporting the hypothesis of transient cavitation effects. The authors proposed that the transient formation of pore-like defects in the liposomal membrane is the main mechanism behind the observed release.

Several research groups performed in vitro studies to evaluate the effect of the liposomal lipid composition on their sonosensitivity [31,174,183,203,204,206]. Evjen et al. [203]
Release of chemotherapeutic drugs from micelles \& liposomes 19 evaluated the sonosensitivity and serum stability of several types of Dox encapsulating-liposomes, composed of different percentages of DSPE (1,2 distearoyl-sn-glycero-3phosphatidylethanolamine), DSPC (1,2 distearoyl-sn-glycero3-phosphatidylcholine), DSPE-PEG2000 ((-N-(methoxy (polyethylene glycol)-2000), and cholesterol. The study showed that DSPE had the largest impact on the liposomal sonosensitivity, with an optimal formulation releasing $70 \%$ of Dox after $6 \mathrm{~min}$ exposure to $40-\mathrm{kHz}$ US, representing a 7 -fold increase relative to standard PEGylated liposomal Dox (Doxil). The results also showed that intermediate levels of DSPE combined with high levels of cholesterol also promoted the sensitivity of the liposomes to US. Additionally, the inclusion of high levels of cholesterol enhanced the stability of the liposomal formulation in serum.

The same group [204,207] subsequently developed liposomes containing DOPE (dioleoylphosphatidylethanolamine), the unsaturated analogue of DSPE, as the main component and compared their performance with HSPC (hydrogenated soy L-aphosphatidylcholine)-based liposomes. In contrast to the latter, it was observed that the liposomal size, size distribution and structure of the DOPE-based liposomes significantly changed after applying US. This indicated that the drug release was caused by a different mechanism in each case, due to the differences in membrane composition. Moreover, it was found that the DOPE-liposomal formulation showed a 30\% increase in US-induced Dox release in vitro (at $40 \mathrm{kHz}$ ), when compared to the previously described DSPE formulation [203], corresponding to a 9-fold improvement when compared to PEGylated liposomal Dox (Doxil). Furthermore, while DSPEbased liposomes showed a decrease in sonosensitivity in serum, the DOPE-based ones still showed the same release properties.

The eLiposomes described previously (section "Liposomes and ultrasound"') were used to study the in vitro release of calcein upon exposure to $20-\mathrm{kHz}$ US [187]. Calcein was encapsulated in eLiposomes containing different size droplets of perfluorohexane $\left(\mathrm{PFC}_{6}\right)$ or perfluoropentane $\left(\mathrm{PFC}_{5}\right)$ emulsions. It was observed that the eLiposomes released 3- to 5-times more calcein upon exposure to US, when compared to control liposomal samples, and that this release increased with the US intensity and exposure time. The calcein release was higher when the liposomes contained 400-nm emulsion droplets, compared to the 100-nm ones, and when $\mathrm{PFC}_{5}$ was used, compared to $\mathrm{PCF}_{6}$. Hence, the authors suggested that the ideal drugdelivery eLiposomal system consists of liposomes with large $\mathrm{PCF}_{5}$ emulsion droplets, but these may not be small enough to extravasate at the tumor site. The same research group also researched the ultrasonic parameters needed to change the phase (from liquid to gas) in these nanoemulsions [208]. More recently, a model was developed to account for the heat, mass and momentum transfer effects responsible for the phase change in $\mathrm{PFC}_{5}$ nanoemulsions, in order to better understand the release phenomena from eLiposomes [10,209]. Their model showed that the maximum bubble size and 
20 S. E. Ahmed et al.

collapse velocity increases with increasing temperature, droplet size, US amplitude and vapor pressure [209].

Javadi and co-workers [189] developed two new methods to prepare eLiposomes, namely the one-step method and the ultra-method. They prepared these eLiposomes with $\mathrm{PFC}_{5}$ or $\mathrm{PFC}_{6}$ nanoemulsions, with a folate ligand, and loaded them with the model drug calcein. Images obtained by cryotransmission electron microscopy provided evidence that eLiposomes could be formed using any of the two new methods, which are faster and less laborious than the original two-step method described by Lattin et al. [191].

The development of a new type of thermosensitive liposomes was recently described by Ninomiya and coworkers [205]. These liposomes are modified with the thermosensitive copolymer (TSP) N-isopropylmethacrylamide (NIPMAM) and N-isopropylacrylamide (NIPAM), named poly(NIPMAM-co-NIPAM), which makes them sensitive to temperature. Calcein release was observed when these liposomes were exposed to $1-\mathrm{MHz}$ US at $0.5 \mathrm{~W} / \mathrm{cm}^{2}$ for $120 \mathrm{~s}$.

\section{In vitro cellular studies}

After confirming the role of US as a trigger for the release of drugs from liposomes, several studies explored the effect of combining liposome-encapsulated drugs and US systems in vitro (Table 5).

The study by Schroeder and co-workers [201] described in the previous section also considered the in vitro effect of $20 \mathrm{kHz}$ LFUS on the cellular uptake and toxicity of cisplatin encapsulated in PEGylated liposomes, by sensitive C26 murine colon adenocarcinoma cells. Aliquots of LFUSreleased cisplatin were added to the cells and the observed cytotoxicity was proportional to the liposome irradiation time. Furthermore, the cytotoxicity of the released cisplatin was equal to that of a similar concentration of the non-irradiated free drug, indicating that the LFUS did not have an effect in the drug biological activity.

Microbubbles have been widely used as contrast agents in diagnostic US [215]. More recently, their use in combination with US, in gene and drug delivery, has been investigated [216]. However, microbubbles have several disadvantages as DDS: they are generally unstable, hence they have short circulation times in vivo [217], they are too large (1-6mm diameter) for extravascular applications [218], they have a very limited drug-loading capacity [217], and their surface is not easily modified with functional molecules to allow targeted delivery [211]. Recently, researchers have been investigating the possibility of using microbubbles [212] and nanobubbles (with 300-700nm diameter [219]) in combination with liposomes for non-invasive targeted drug delivery under image guidance.

Lentacker et al. [210] compared the US-induced delivery of Dox-containing liposomes and Dox-liposome-containing microbubbles. The latter was prepared by attaching biotinylated Dox-containing liposomes to the surface of a biotinylated lipid microbubble containing perfluorobutane,
J Drug Target, Early Online: 1-33 with the aid of an avidin molecule. In vitro studies using a melanoma BLM cell line showed that when this microbubbleliposome system was exposed to 1-MHz US, there was a 2-fold increase in cell death, when compared to regular liposomes. This was due to an enhanced cellular uptake of the Dox released from the system by the action of US, followed by an accumulation of Dox in the nuclei of the cancer cells. When regular liposome-encapsulated Dox was used, the drug was distributed in the cytoplasm and nucleus of the cells. The authors hypothesized that the increased cellular uptake was caused by the sonoporation of the cellular membrane, due to the implosion of the microbubbles under the action of US. The microbubble-liposome-US system appears to be promising in enhancing the in vivo efficacy of Doxil, while at the same time causing fewer side effects.

The same group [212] also developed similar microbubbles but with Dox-containing liposomes coupled to the microbubble surface by covalent thiol-maleimide linkages. They used 1.7-MHz US with a mechanical index of 0.2 and showed that the microbubbles scattered enough signal to be imaged in real time and be used in vivo. Their in vitro studies in human glioblastoma (U-87 MG) cells showed a 4-fold decrease in cell viability when the microbubble system was used in conjunction with $1-\mathrm{MHz}$ US and pressures up to $600 \mathrm{kPa}$, when compared to the controls: free Dox or noninsonated Dox-loaded liposome-microbubbles. The cell viability results are correlated to an increase of encapsulated Dox triggered by US as well as an enhanced uptake of Dox by the cancer cells.

Ueno and co-workers [211] developed AAL with perfluoropropane gas, as a carrier for Dox and studied their effect in a murine osteosarcoma cell line (LM8), when used in conjunction with $1-\mathrm{MHz}$ US, with a power density of $0.5 \mathrm{~W} / \mathrm{cm}^{2}$, and a duty cycle of $50 \%$ for a 10 s cycle duration. By comparison with controls (non-treated cells, cells treated with Dox alone, cells treated with Dox and AAL, cells treated with Dox and US), it was observed that the effect of Dox was significantly enhanced when treated with AAL and US. Since an in vitro EPR effect is highly unexpected, these results are mainly explained by an increased drug uptake induced by cavitation and sonoporation.

Javadi et al. $[189,190]$ used the folated eLiposomes with $\mathrm{PFC}_{5}$ nanoemulsions, described previously, to study the delivery of calcein to HeLa cells, upon application of $20-\mathrm{kHz}$ US, with a power density of $1 \mathrm{~W} / \mathrm{cm}^{2}$, for $2 \mathrm{~s}$. Confocal microscopy images showed that both the surface folate ligand and the nanoemulsions were required to deliver a significant amount of calcein to the cytosol of the HeLa cells. The same authors [190] obtained similar results when using eLiposomes carrying a model green fluorescent protein (GFP) plasmid, observing that plasmid transfection of HeLa cells was greatly enhanced by the application of low-frequency low-intensity US.

Afadzi and co-workers [213] studied the effect of $300-\mathrm{kHz}$ US and microbubbles on the cellular uptake of Dox-containing DEPC (dierucoyl-phosphatidylcholine) liposomes and FITC 
DOI: $10.3109 / 1061186$ X.2014.954119

(fluorescein-isothiocyanate)-dextran by $\mathrm{HeLa}$ cells. Their study tried to unravel the mechanism behind the uptake, whether it was sonoporation or endocytosis. The results showed an increase in the cellular uptake of liposomes and
Release of chemotherapeutic drugs from micelles \& liposomes 21 dextran when US was combined with microbubbles, suggesting an extracellular disruption of liposomes followed by drug 


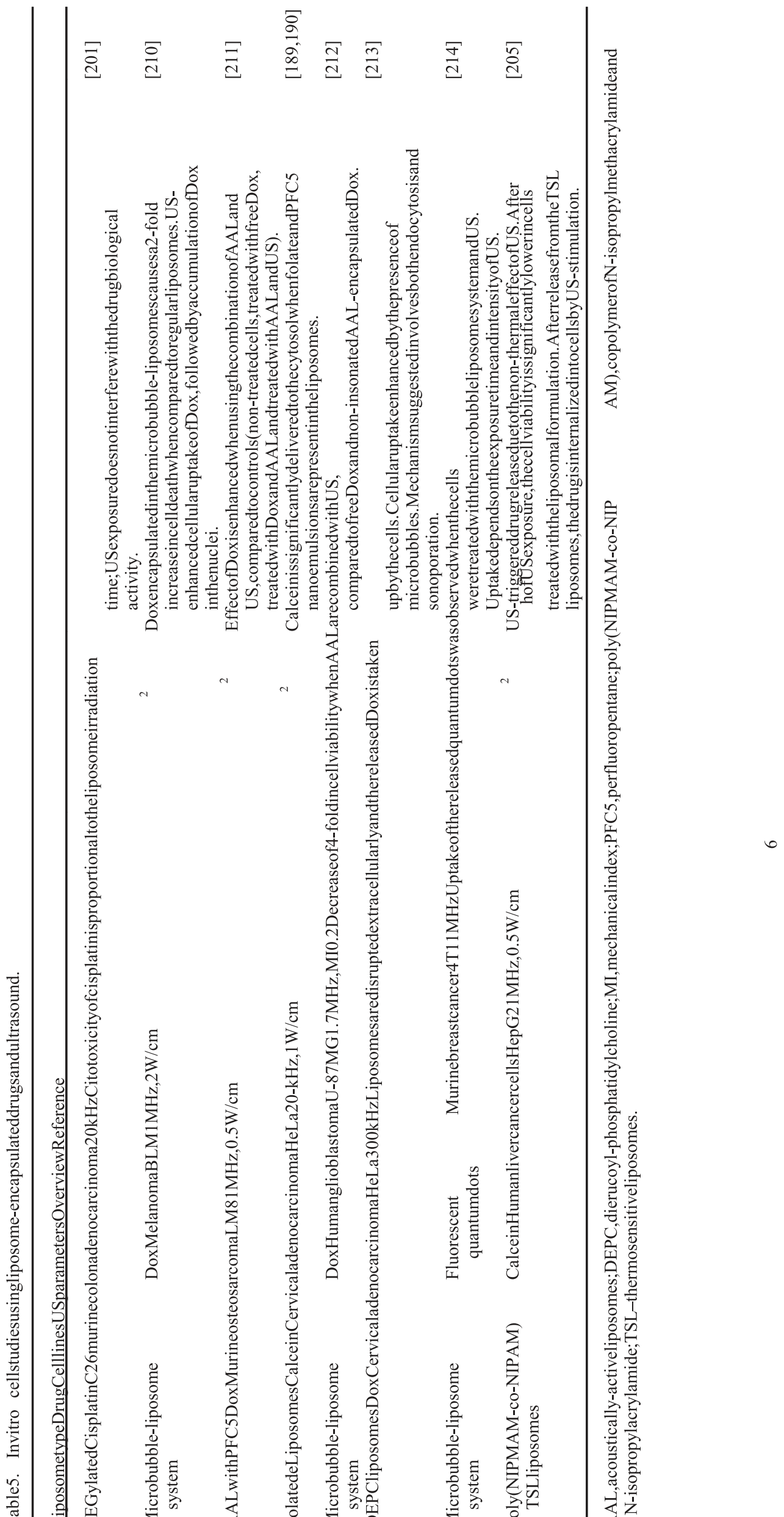


DOI: 10.3109/1061186X.2014.954119

uptake. Experiments using endocytosis-inhibitors evidenced that endocytosis is part of the uptake mechanism, but that sonoporation is also part of the process.

Recently, Yan et al. [214] reported the use of Paclitaxelliposomes conjugated to microbubbles (using the strong biotin/avidin interactions). The results showed an increase, both in vitro and in vivo, of drug release when US was applied. This increase was statistically significant when compared to release without US or release in the absence of microbubbles. Histological studies showed an increased inhibition of tumor angiogenesis and proliferation when using the complexed microbubbles.

The group of Endo-Takahashi [220] succeeded in encapsulating a microbubble contrast agent in a PEG-modified stealth liposomal formulation. Upon HFUS application, pDNA and siRNA delivery was demonstrated. The group concluded that such AAL can serve both as gene delivery carriers as well as diagnostic probes.

In vivo studies using animal models and clinical trials

There are very few in vivo studies reporting the effect of US triggering on Doxil (Table 6). However; a number of researchers have conducted in vivo, preclinical and clinical trials that utilize liposomes without US as an effective Dox DDS.

Papahadjopoulos and co-workers [180] described the use of stealth (PEGylated) liposomes and studied the pharmacokinetics and therapeutic efficiency of encapsulated Dox and epirubicin in mice models with lymphomas and colon carcinomas. Their results showed a marked increase in the therapeutic effects of both drugs, since there was a decrease in the size of the tumors in laboratory mice treated with the new formulation when compared to the tumor size of nontreated animals or animals treated with the free form of the drugs. Additionally, they observed a significant decrease of the uptake of the drugs by other tissues including the liver and spleen, with the drugs accumulating preferentially in the tumor tissues.

Several other studies were performed using Doxil in various rodent tumors and human xenografts in immunodeficient mice and dogs, all of which reported an evidence of increased efficacy and circulation half-life of Doxil in comparison with free and non-PEGylated liposomal Dox [210,212,224-226]. Further studies [227,228] on rabbit and dog models, implanted with murine and human xenograft tumors and treated with Caelyx, reported the advantage of using Dox encapsulated in stealth liposomes to reduce the drug cardiotoxicity. These studies, although not utilizing US, emphasized the use of liposomes as effective drug delivery vehicles.

The effect of sonicating Doxil when used as a DDS in murine models was reported by Yuh et al. [221]. The group studied the effect of pulsed 1.5-MHz HFUS as a Doxil release trigger in mice bearing a murine squamous carcinoma (SCC7 cell line), then compared their results with a second group of mice treated with Dox alone, and a third control group of
Release of chemotherapeutic drugs from micelles \& liposomes 23 untreated animals. The researchers observed an increased concentration of Dox in tumors and higher extravasation of dextran-fluorescein isothyocyanate in the vasculature of malignant tissue when US was applied. Although not conclusive, this work suggested hyperthermia and/or cavitation as the possible mechanisms behind these USinduced results.

Myhr and Moan [161] studied the effect of the application of LFUS $(20 \mathrm{kHz})$ on a group of $144 \mathrm{Balb} / \mathrm{c}$ nude mice inoculated with a human colon tumor cell line (WiDr) to release Dox encapsulated in PEGylated liposomes (Caelyx) at different Dox concentrations ( 3 and $6 \mathrm{mg} / \mathrm{kg}$ ). The experiments reported, for the first time, the non-hyperthermic effect of US on the drug release, and revealed the synergistic and tumorselective effects of the combination of US and Caelyx. Furthermore, it was observed that the synergistic effects were more significant when low drug concentrations were used.

The effect of pulsed HIFU was studied by the group of Frenkel et al. [222], who administered Doxil to female syngeneic Balb/c mice inoculated with a murine mammary adenocarcinoma cell line (JC) and female $\mathrm{C} 3 \mathrm{H}$ mice inoculated with a murine squamous cell carcinoma line (SCC7). The researchers used 1-MHz pulsed US, at a spatial average power density of $124 \mathrm{~W} / \mathrm{cm}^{2}$ in the treatment, and observed that sonication showed a safe behavior on the overall health of the mice, and had the ability to harm irradiated cancer cells. However, the Doxil/US combination failed to improve Dox uptake by tumors, and thus failed to allow for lower Dox dosages to be used in combination with US.

Different results were obtained by the same group [200] when performing in vivo studies with the LTSL described in the previous section. These authors used a murine mammary adenocarcinoma (JC) female BALB/c mice model to study the combination of LTSL with noninvasive and nondestructive $1 \mathrm{MHz}$ HFUS, and observed delayed tumor growth caused by an enhanced delivery of Dox. No increase in Dox concentration in the tumors was observed when using pulsedHIFU combined with either Doxil or free Dox, emphasizing the importance of hyperthermia and LTSL in the process.

To complement the previously described in vitro work, Ueno et al. [211], studied the in vivo effects of a combination of Dox, AAL and US, in osteosarcoma-bearing mice models ( $\mathrm{C} 3 \mathrm{H}$ female mice with LM8 tumors). The mice were divided into eight groups: (i) untreated mice; (ii) free Dox $(1 \mathrm{mg} / \mathrm{kg})$; (iii) Dox (1mg/kg)+AAL+US; (iv) free Dox (5mg/kg); (v) free Dox (1 mg/kg)+US; (vi) AAL alone; (vii) US alone; and (viii) AAL+US. Ultrasound was used three times in nonconsecutive days, in groups (iii), (v), (vii) and (viii) with a frequency of $2 \mathrm{MHz}$, a power density of $2 \mathrm{~W} / \mathrm{cm}^{2}$, a $50 \%$ duty cycle, a burst rate of $2 \mathrm{~Hz}$, and a cycle duration of $60 \mathrm{~s}$. The results showed that the group treated using the combination of Doxil and US (group (iii)) had the highest survival, drug uptake and tumor regression rates, despite utilizing the lowest Dox concentration, $1 \mathrm{mg} / \mathrm{kg}$, which is 5 times lower than the concentration used in group (iv). No difference was observed between the hepatic Dox concentrations in groups (iii) and (v), 
24 S. E. Ahmed et al.

indicating a decrease in the drug uptake by the reticuloendothelial system. This was attributed to the preparation method of Dox-AAL liposomes and Dox were simply mixed, instead of Dox being sealed inside the liposomes. 


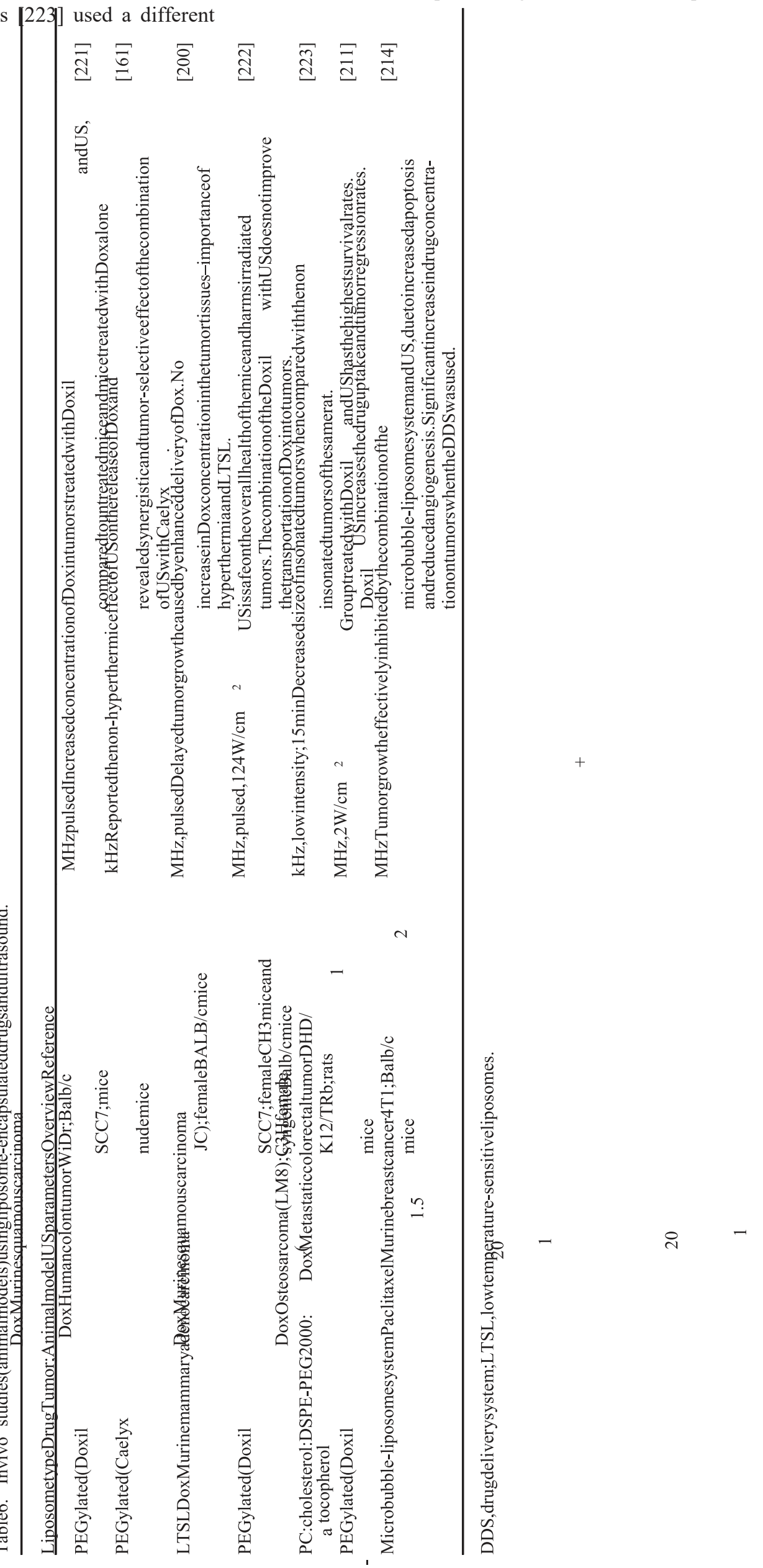


26 S. E. Ahmed et al.

approach to study the release and delivery of Dox from PC:cholesterol:DSPE-PEG2000:alpha-tocopherol stealth liposomes. They applied long durations (15min), of lowfrequency $(20 \mathrm{kHz})$ low-intensity US, to one of the hind legs of rats with bilateral intradermal DHD/K12/TRb metastatic colorectal tumors, after injecting their tail vein with encapsulated Dox. The therapy was repeated weekly and lasted 4 weeks. The study reported a statistically significant regression of tumor size in insonated tumors when compared with the non-insonated tumors of the same rat.

Treat and co-workers [229] used magnetic resonance image (MRI)-guided focused US (1.6MHz) to permeabilise the blood-brain barrier (BBB) and the blood-tumor barrier (BTB) in normal male Sprague-Dawley rats, and allow the delivery of Doxil. It was observed that the Dox concentration in targeted rats' brain cells reached the therapeutic levels needed to cure human tumors while the concentrations in the non-targeted tissues remained low, resulting in a reduction in the unwanted side effects. These results were especially promising, since several potential drugs for brain chemotherapy (such as Dox) are not able to cross the BBB. Further research on the kinetics of the BBB disruption and the factors affecting its permeability were discussed by Nhan et al. [230].

Similarly, in a recent work, Aryal et al. [231] conducted experiments on glioma-bearing rats that were divided into four groups: (i) a group treated with Doxil and exposed to $700-\mathrm{kHz}$ focused US; (ii) a group treated with Doxil alone; (iii) a group irradiated without Dox or liposomes; and (iv) a non-treated control group. The main challenge in these experiments was to design a DDS that is capable of crossing the BBB. Results showed a considerable increase in survival rates and a types of cancer $[76,234,235]$. However, to the best of our knowledge, no clinical trials were ever conducted to test the effects of US in cancer chemotherapy using other nanocarriers. A phase II clinical trial denominated MRI Guided High Intensity Focused Ultrasound (HIFU) and ThermoDox for Palliation of Painful Bone Metastases, is described at the ClinicalTrials.gov website (http://clinicaltrials.gov/ct2/show/ study/NCT01640847), but has not yet been scheduled to begin. The following are examples of preclinical or clinical studies using Doxil (without using ultrasound).

The use of PEGylated liposomes as Dox carriers have been used efficiently in the treatment of breast [236], ovarian [237], colon [238], bladder [239], pancreas [240], and lung [16], cancers as well as in lymphomas [241], myelomas and sarcomas [16]. As mentioned previously, the system is also capable of crossing the BBB that restricts the delivery of the majority of anti-tumor drugs to the central nervous system and hinders their transport into brain tumors [242].

Examples of clinical trials include the study of Harrington et al. [243], who conducted a phase II trial on Caelyx administered to 20 treatment-nar"ve patients with squamous cell cancer of the head and neck (SCCHN). They found Caelyx to be appreciably active against SCCHN, especially if used in conjunction with radical radiotherapy. The reported side effects were minimal.
J Drug Target, Early Online: 1-33 statistically significant regression in tumor size in the first group when compared to the others, which indicated a successful temporal disruption of the BBB by the focused US multiple exposures. Unfortunately, the treatment had several side effects such as the damage of adjacent brain tissue, skin toxicity, and an extensive intratumoral hemorrhage in one of the rats treated with Dox combined with US.

The two previously mentioned studies indicate that the combination of Doxil and US is promising in the treatment of glioma, although further research should be conducted in the area of central nervous system malignancies, in order to obtain better results and to diminish the side effects.

The group of Evjen [232] used liposomes synthesized using DOPE, in conjunction with 1.1-MHz US, to show the acoustic enhancement effect in vivo, in athymic nude Balb/c mice inoculated with human prostate tumor cells (22Rv1). The liposomes encapsulated a near-infrared fluorochrome, and the results showed that the DOPE-based liposomes showed enhanced sonosensitivity when compared to HSPC liposomes.

Rizzitelli and co-workers [233] loaded liposomes with a paramagnetic drug and used (1) pulsed low-intensity nonfocused US to release the agent from these carriers and increase its accumulation in vivo, on mice with syngeneic B16 melanoma, and (2) MRI to trace the location of this magnetically sensitive molecule. The group reported a $35 \%$ increase in the magnetic signal upon a $1.5 \mathrm{-MHz}$ US exposure for $2 \mathrm{~min}$.

Several liposomal formulations are either in clinical trials or already being clinically used for the treatment of several

Perez and co-workers [236] studied the effect of Doxil on a group of 40 patients with metastatic breast cancer. The study reported a remarkable progress in survival rates and a significant decrease in drug systemic toxicity when compared to cases treated with free Dox. A Doxil dosage of $40-45 \mathrm{mg} / \mathrm{m}^{2}$ every four weeks was recommended and well-tolerated by the patients.

Several research groups inspected the use of Doxil/ Caelyx/LipoDox as a DDS in phase II clinical trials carried on advanced cases of patients' ovarian cancer refractory to platinum and paclitaxel [237,244-248]. All these clinical trials reported high efficacy, improved safety profiles and patients tolerance of liposome encapsulated Dox activity against ovarian cancer.

\section{Conclusion and future direction}

Several cancers and their developments have been proven to be caused by viruses. The FDA approval of the Human Papilloma Virus vaccine is one example that has the potential of changing our fight against this disease (namely cervical cancer). Other viruses have also been linked to cancers including Hepatitis B (liver cancer), Epstein-Barr Virus (Burkitt Lymphoma), Human Herpes Virus (Kaposi sarcoma). It is not inconceivable that within the next ten to twenty years, a vaccine can be administered to toddlers that will drastically 
DOI: 10.3109/1061186X.2014.954119

reduce their chances of getting most cancers later on in their lives. Another promising area in our fight is gene delivery both viral and non-viral. Viral gene delivery lacks specificity while non-viral is limited by low transfection rates. However, gene delivery and therapy has made considerable strides in recent years.

In the meantime, cancer drug delivery will focus on finding better ways to improve the lives of cancer patients undergoing chemotherapy. As the paper detailed, there are three main principles behind using nanocarriers in drug delivery, namely: passive, active and triggered targeting. In a recent article, Hollis et al. [249] reported that passive targeting (otherwise known as the enhanced retention and permeation effect) was responsible for approximately $1 \%$ of the drug accumulation due to the leaky capillaries of the tumor angiogenesis. However, the passive targeting is the main premise of liposomal Dox (Doxil) which has been effective in treating several types of cancers while at the same time lowering the systemic concentration of the antineoplastic agent and thus reducing the undesired side effects of conventional chemotherapy. There is no doubt that the question of whether passive targeting plays a role in DDS will be researched extensively in the future. As far as active targeting goes, the increased accumulation via receptor-ligand binding will be heavily researched and will play an essential role in future DDS approved for clinical use. The challenge here would be to make sure that the targeting moiety will not affect the stability of the carrier or the efficacy of the chemotherapeutic agent. Some tumor cells overexpress protein receptors. Will labelling the drug delivery vehicles with these large molecules affect their stability, loading capacity and release profiles? Future research will answer this important question. Finally, the third principle employed for effective delivery is triggered targeting. This can be achieved by internal $(\mathrm{pH}$, enzymes, temperature or pressure) or external (light, US, magnetic or electrical fields) means. The challenge when dealing with triggers is to find the proper treatment window where the therapeutic effect is observed while the side effects of the internal or external stimulus are minimized. We believe that employing passive, active and triggered targeting into one multimodal drug delivery system can maximize the effectiveness of future DDS while keeping their associated unwanted effects at bay. We will discuss an example of an ideal chemotherapeutic DDS that employs all three targeting mechanism.

Since passive targeting happens naturally if the size is small enough, the ideal drug-delivery carrier has to be below $0.5 \mathrm{~mm}$. As far as active targeting goes, the most essential aspect of this type of targeting is the correct selection of the moiety/ligands that has the ability to deliver the carrier to the target site, and induce endocytosis. Once inside the lysosome/endosome, the drug needs to be released into the cytosol. This can be achieved using proton sponges and fusogenic peptides/lipids. The only drawback to using these drug release activators into the cytosol is their toxicity. Therefore, it is a good idea to look for other ways to burst the carrier and the endosome when needed. An external trigger mechanism can be helpful here. Ultrasound is
Release of chemotherapeutic drugs from micelles \& liposomes 27 among the most researched stimuli in drug delivery because it is non-invasive and can easily be focused on the cancerous target. In order to make these drug delivery vehicles sensitive to acoustic power, two main strategies can be taken: either using microbubbles that are decorated with the drugencapsulated carriers or by causing the phase change to occur inside the carrier. The latter can be done by encapsulating a liquid emulsion inside the carrier. The phase change can be induced by a small spark or nudge using US since the latter can raise the temperature of the nanoemulsion above its boiling point. Obviously, it is essential that these nanoemulsions are formed using non-toxic compounds.

Once at the desired location/tissue, this ideal DDS should have the ability to control the time of drug release from the carrier, otherwise the drug may be quickly released upon arrival, or we may observe a sustained slow release over time. A slow release may prove problematic since the drug never reaches the appropriate concentrations for the desired therapy which in turn may expedite the development of multidrug resistance in the malignant tissue. Therefore, in most cases, it is highly desirable to release the majority of the drug instantly and simultaneously to achieve a rapid high and lethal concentration. Here, US appears to be a perfect trigger.

Finally, it is worth mentioning that whenever US is utilized, its parameters have to be optimized to reach the desired therapeutic effect while minimizing the damage to the adjacent health tissues. These parameters include the power density, acoustic frequency, whether continuous or pulsed US is used, and pulse duration if that latter was used.

In conclusion, we reiterate that advances in the area of drug delivery and the insisting need to reduce the undesired side effects caused by chemotherapeutic agents have encouraged researchers to seek the development of new DDS that are selective, safe and efficacious. This paper reviewed two promising drug delivery carriers currently investigated in chemotherapy, namely liposomes and micelles, administered in combination with US. Although no clinical trials have been conducted to test the feasibility of administering chemotherapeutic drugs and US to treat cancer, several reported in vivo studies suggest that improved results, with fewer side effects, can be obtained in the future.

\section{Declaration of interest}

The authors report no declarations of interest. The authors acknowledge the financial support of the Faculty Research Grant Type 1, from American University of Sharjah (to G.A. Husseini).

\section{References}

1. Thierry B. Drug nanocarriers and functional nanoparticles: applications in cancer therapy. Curr Drug Deliv 2009;6:391-403.

2. Mozafari MR. Nanocarrier technologies: frontiers of nanotherapy. Dordrecht: Springer; 2006.

3. Mozafari MR, Pardakhty A, Azarmi S, et al. Role of nanocarrier systems in cancer nanotherapy. J Liposome Res 2009;19:310-21.

4. Pitt WG, Husseini GA. Ultrasound in drug and gene delivery. Adv Drug Deliv Rev 2008;60:109-56. 
28 S. E. Ahmed et al.

5. Ulrich AS. Biophysical aspects of using liposomes as delivery vehicles. Biosci Rep 2002;22:129-50.

6. Ferrara KW. Driving delivery vehicles with ultrasound. Adv Drug Deliv Rev 2008;60:1097-102.

7. Lasic D. Liposomes: synthetic lipid microspheres serve as multipurpose vehicles for the delivery of drugs, genetic material and cosmetics. American Scientist 1992;80:20-31.

8. Husseini GA, Pitt WG. Micelles and nanoparticles for ultrasonic drug and gene delivery. Adv Drug Deliv Rev 2008;60:1137-52.

9. Blanco E, Kessinger CW, Sumer BD, Gao J. Multifunctional micellar nanomedicine for cancer therapy. Exp Biol Med (Maywood) 2009;234:123-31.

10. Pitt WG, Husseini GA, Kherbeck LN. Ultrasound-triggered release from micelles. In: Alvarez-Lorenzo C, Concheiro A, eds. Smart materials for drug delivery, Vol. 1, Chapter 6. RSC Publishing; 2013:148-78.

11. Siepmann J, Siegel R. Fundamentals and applications of controlled release drug delivery. New York: Springer; 2012.

12. Sirsi SR, Borden MA. State-of-the-art materials for ultrasoundtriggered drug delivery. Adv Drug Deliv Rev 2014;72C:3-14.

13. Papagiannaros A, Demetzos C. Release advantages of a liposomal dendrimer-doxorubicin complex, over conventional liposomal formulation of doxorubicin. In: Mozafari MR, ed. Nanomaterials and nanosystems for biomedical applications. Dordrecht: Springer; 2007:135-44.

14. Wooster R, Weber BL. Breast and ovarian cancer. N Engl J Med 2003;348:2339-47.

15. Sharpe M, Easthope SE, Keating GM, Lamb HM. Polyethylene glycol-liposomal doxorubicin: a review of its use in the management of solid and haematological malignancies and AIDSrelated Kaposi's sarcoma. Drugs 2002;62:2089-126.

16. Gabizon AA. Pegylated liposomal doxorubicin: metamorphosis of an old drug into a new form of chemotherapy. Cancer Invest 2001; 19:424-36.

17. Gewirtz DA. A critical evaluation of the mechanisms of action proposed for the antitumor effects of the anthracycline antibiotics adriamycin and daunorubicin. Biochem Pharmacol 1999;57: 72741.

18. Chatterjee K, Zhang J, Honbo N, Karliner JS. Doxorubicin cardiomyopathy. Cardiology 2010;115:155-62.

19. Chlebowski RT. Adriamycin (doxorubicin) cardiotoxicity: a review. West J Med 1979;131:364-8.

20. Shi Y, Moon M, Dawood S, et al. Mechanisms and management of doxorubicin cardiotoxicity. Herz 2011;36:296-305.

21. Allen TM, Hansen CB, De Menezes DEL. Pharmacokinetics of long-circulating liposomes. Adv Drug Deliv Rev 1995;16: 267-84.

22. Sutton D, Nasongkla N, Blanco E, Gao J. Functionalized micellar systems for cancer targeted drug delivery. Pharm Res 2007;24: 1029-46.

23. Wang S, Mi JB, Li YZ, et al. Pharmacokinetics and tissue distribution of iv injection of polyphase liposome-encapsulated cisplatin (KM-1) in rats. Acta Pharmacol Sin 2003;24:589-92.

24. Forssen EA, Tokes ZA. Use of anionic liposomes for the reduction of chronic doxorubicin-induced cardiotoxicity. Proc Natl Acad Sci USA 1981;78:1873-7.

25. Juliano RL, Stamp D, Mccullough N. Pharmacokinetics of liposome-encapsulated antitumor drugs and implications for therapy. Ann N Y Acad Sci 1978;308:411-25.

26. Maurer N, Fenske DB, Cullis PR. Developments in liposomal drug delivery systems. Expert Opin Biol Ther 2001;1:923-47.

27. Leighton TG. What is ultrasound? Prog Biophys Mol Biol 2007;93: 3-83.

28. Hall DO, Selfridge AR. Multi-frequency ultrasound therapy systems and methods. Google Patents. USA: Dynatronics Laser Corporation; 1995.

29. Mitragotri S Kost J. Low-frequency sonophoresis: a review. Adv Drug Deliv Rev 2004;56:589-601.
J Drug Target, Early Online: 1-33

30. Liu Y, Miyoshi H, Nakamura M. Encapsulated ultrasound microbubbles: therapeutic application in drug/gene delivery. $\mathrm{J}$ Control Release 2006;114:89-99.

31. Schroeder A, Kost J, Barenholz Y. Ultrasound, liposomes, and drug delivery: principles for using ultrasound to control the release of drugs from liposomes. Chem Phys Lipids 2009;162:1-16.

32. Van Wamel A, Kooiman K, Harteveld $M$, et al. Vibrating microbubbles poking individual cells: drug transfer into cells via sonoporation. J Control Release 2006;112:149-55.

33. Klibanov AL, Shevchenko TI, Raju BI, et al. Ultrasound-triggered release of materials entrapped in microbubble-liposome constructs: a tool for targeted drug delivery. J Control Release 2010;148:1317.

34. Frenkel V. Ultrasound mediated delivery of drugs and genes to solid tumors. Adv Drug Deliv Rev 2008;60:1193-208.

35. Draper DO, Castel JC, Castel D. Rate of temperature increase in human muscle during $1 \mathrm{MHz}$ and $3 \mathrm{MHz}$ continuous ultrasound. $\mathrm{J}$ Orthop Sports Phys Ther 1995;22:142-50.

36. Huber PE, Debus J. Tumor cytotoxicity in vivo and radical formation in vitro depend on the shock wave-induced cavitation dose. Radiat Res 2001;156:301-9.

37. Huber PE, Jenne JW, Rastert R, et al. A new noninvasive approach in breast cancer therapy using magnetic resonance imaging-guided focused ultrasound surgery. Cancer Res 2001;61: 8441-7.

38. Lu XQ, Burdette EC, Bornstein BA, et al. Design of an ultrasonic therapy system for breast cancer treatment. Int J Hyperthermia 1996;12:375-99.

39. Nyborg WL. Biological effects of ultrasound: development of safety guidelines. Part II: general review. Ultrasound Med Biol 2001;27:301-33.

40. Underwood HR, Burdette EC, Ocheltree KB, Magin RL. A multielement ultrasonic hyperthermia applicator with independent element control. Int J Hyperthermia 1987;3:257-67.

41. Pitt WG, Husseini GA, Staples BJ. Ultrasonic drug delivery - a general review. Expert Opin Drug Deliv 2004;1:37-56.

42. Saad AH, Hahn GM. Ultrasound enhances adriamycin toxicity in vitro. In: Chato JC, Diller TE, Diller KR, Roemer RB, eds. Heat transfer in bioengineering and medicine. New York: Am Soc Mech Eng. Press; 1987:28-31.

43. Collis J, Manasseh R, Liovic P, et al. Cavitation microstreaming and stress fields created by microbubbles. Ultrasonics 2009;50: 273-9.

44. Marmottant P, Hilgenfeldt S. Controlled vesicle deformation and lysis by single oscillating bubbles. Nature 2003;423:53-6.

45. Nyborg WL. Ultrasonic microstreaming and related phenomena. $\mathrm{Br}$ J Cancer Suppl 1982;5:156-60.

46. Brennen CE. Cavitation and bubble dynamics. New York: Oxford University Press; 1995.

47. Furusawa Y, Hassan MA, Zhao QL, et al. Effects of therapeutic ultrasound on the nucleus and genomic DNA. Ultrason Sonochem 2014;21:2061-8.

48. May DJ, Allen JS, Ferrara KW. Dynamics and fragmentation of thick-shelled microbubbles. IEEE Trans Ultrason Ferroelectr Freq Control 2002;49:1400-10.

49. Rooney JA. Hemolysis near an ultrasonically pulsating gas bubble. Science 1970;169:869-71.

50. Rooney JA. Ultrasound: its chemical, physical, and biological effects. Cambridge: VCH Publishers; 1988:74-96.

51. Williams AR, Miller DL. Photometric detection of ATP release from human erythrocytes exposed to ultrasonically activated gasfilled pores. Ultrasound Med Biol 1980;6:251-6.

52. Oerlemans C, Deckers R, Storm G, et al. Evidence for a new mechanism behind HIFU-triggered release from liposomes. J Control Release 2012;168:327-33.

53. Deckers R, Moonen CT. Ultrasound triggered, image guided, local drug delivery. J Control Release 2010;148:25-33.

54. Hernot S, Klibanov AL. Microbubbles in ultrasound-triggered drug and gene delivery. Adv Drug Deliv Rev 2008;60:1153-66. 
DOI: 10.3109/1061186X.2014.954119

55. Husseini GA, Myrup GD, Pitt WG, et al. Factors affecting acoustically triggered release of drugs from polymeric micelles. J Control Release 2000;69:43-52.

56. Husseini GA, Pitt WG. The use of ultrasound and micelles in cancer treatment. J Nanosci Nanotechnol 2008;8:2205-15.

57. Hwang JH, Crum LA. Current status of clinical high-intensity focused ultrasound. 31st Annual International Conference of the IEEE EMBS; 2009.

58. Yu T, Wang Z, Mason TJ. A review of research into the uses of low level ultrasound in cancer therapy. Ultrason Sonochem 2014;11: 95-103.

59. Peer D, Karp JM, Hong S, et al. Nanocarriers as an emerging platform for cancer therapy. Nat Nanotechnol 2007;2:751-60.

60. Byrne JD, Betancourt T, Brannon-Peppas L. Active targeting schemes for nanoparticle systems in cancer therapeutics. Adv Drug Deliv Rev 2008;60:1615-26.

61. Torchilin VP. Micellar nanocarriers: pharmaceutical perspectives. Pharm Res 2007;24:1-16.

62. Dua JS, Rana AC, Bhandari AK. Liposome: methods of preparation and applications. Int J Pharm Stud Res 2012;3:14-20.

63. Frezard F. Liposomes: from biophysics to the design of peptide vaccines. Braz J Med Biol Res 1999;32:181-9.

64. Maeda H. The enhanced permeability and retention (EPR) effect in tumor vasculature: the key role of tumor-selective macromolecular drug targeting. Adv Enzyme Regul 2001;41:189-207.

65. Maeda $\mathrm{H}, \mathrm{Wu}$ J, Sawa T, et al. Tumor vascular permeability and the EPR effect in macromolecular therapeutics: a review. J Control Release 2000;65:271-84.

66. Danson S, Ferry D, Alakhov V, et al. Phase I dose escalation and pharmacokinetic study of pluronic polymer-bound doxorubicin (SP1049C) in patients with advanced cancer. Br J Cancer 2004;90: 2085-91.

67. Gabizon A, Sulkes A, Peretz T, et al. Liposome-associated doxorubicin: preclinical pharmacology and exploratory clinical phase. In: Fidler IJ, Lopez-Berestein G, eds. Liposomes in the therapy of infectious diseases and cancer. New York: ARL; 1989:391-402.

68. Hayama A, Yamamoto T, Yokoyama M, et al. Polymeric micelles modified by folate-PEG-lipid for targeted drug delivery to cancer cells in vitro. J Nanosci Nanotechnol 2008;8:3085-90.

69. Kabanov AV. Polymer genomics: an insight into pharmacology and toxicology of nanomedicines. Adv Drug Deliv Rev 2006;58: 1597-621.

70. Treat J, Greenspan AR, Rahman A. Liposome-encapsulated doxorubicin. Preliminary results of phase-I and phase-II trials. In: Lopez-Berestein, G, Fidler IJ, eds. Liposomes in the therapy of infectious diseases and cancer. New York: ARL; 1989;353-65.

71. Van Hoesel QG, Steerenberg PA, Crommelin DJ, et al. Reduced cardiotoxicity and nephrotoxicity with preservation of antitumor activity of doxorubicin entrapped in stable liposomes in the LOU/M Wsl rat. Cancer Res 1984;44:3698-705.

72. Goyal PS, Aswal VK. Micellar structure and inter-micelle interactions in micellar solutions: results of small angle neutron scattering studies. Curr Sci 2001;80:353-65.

73. Sudho"lter EJR, Van DE, Langkruis GB, Engberts JBFN. Micelles. Structure and catalysis. Recueil des Travaux Chimiques des PaysBas 1980;99:73-82.

74. Xu W, Ling P, Zhang T. Polymeric micelles, a promising drug delivery system to enhance bioavailability of poorly water-soluble drugs. J Drug Deliv 2013;2013:340315 (1-15).

75. Kedar U, Phutane $P$, Shidhaye $S$, Kadam V. Advances in polymeric micelles for drug delivery and tumor targeting. Nanomedicine 2010;6:714-29.

76. Khan DR. The use of nanocarriers for drug delivery in cancer therapy. J Cancer Sci Ther 2010;2:058-62.

77. Oerlemans C, Bult W, Bos M, et al. Polymeric micelles in anticancer therapy: targeting, imaging and triggered release. Pharm Res 2010;27:2569-89.
Release of chemotherapeutic drugs from micelles \& liposomes 29

78. Adams ML, Lavasanifar A, Kwon GS. Amphiphilic block copolymers for drug delivery. J Pharm Sci 2003;92:1343-55.

79. Gaucher G, Dufresne MH, Sant VP, et al. Block copolymer micelles: preparation, characterization and application in drug delivery. J Control Release 2005;109:169-88.

80. Husseini GA, Pitt WG. Ultrasonic-activated micellar drug delivery for cancer treatment. J Pharm Sci 2009;98:795-811.

81. Husseini GA, El-Fayoumi RI, O'neill KL, et al. DNA damage induced by micellar-delivered doxorubicin and ultrasound: comet assay study. Cancer Lett 2000;154: 211-16.

82. Husseini GA, Rapoport NY, Christensen DA, et al. Kinetics of ultrasonic release of doxorubicin from pluronic P105 micelles. Colloids Surf 2002;24:253.

83. Marin A, Sun H, Husseini GA, et al. Drug delivery in pluronic micelles: effect of high-frequency ultrasound on drug release from micelles and intracellular uptake. J Control Release 2002;84:3947.

84. Muniruzzaman MD, Marin A, Luo Y, et al. Intracellular uptake of pluronic copolymer: effects of the aggregation state. Colloids Surf B 2002;25:233-41.

85. Munshi N, Rapoport N, Pitt WG. Ultrasonic activated drug delivery from Pluronic P-105 micelles. Cancer Lett 1997;118:13-19.

86. Rapoport NY, Herron JN, Pitt WG, Pitina L. Micellar delivery of doxorubicin and its paramagnetic analog, ruboxyl, to HL-60 cells: effect of micelle structure and ultrasound on the intracellular drug uptake. J Control Release 1999;58:153-62.

87. Uhrich KE, Cannizzaro SM, Langer RS, Shakesheff KM. Polymeric systems for controlled drug release. Chem Rev 1999; 99:3181-98.

88. Ogris M, Brunner S, Schuller S, et al. PEGylated DNA/transferrinPEI complexes: reduced interaction with blood components, extended circulation in blood and potential for systemic gene delivery. Gene Ther 1999;6:595-605.

89. Romberg B, Hennink WE, Storm G. Sheddable coatings for longcirculating nanoparticles. Pharm Res 2008;25:55-71.

90. Pruitt JD, Husseini G, Rapoport N, Pitt WG. Stabilization of pluronic p-105 micelles with an interpenetrating network of n,ndiethylacrylamide. Macromolecules 2000;33:9306-9.

91. Husseini GA, Christensen DA, Rapoport NY, Pitt WG. Ultrasonic release of doxorubicin from Pluronic P105 micelles stabilized with an interpenetrating network of N,N-diethylacrylamide. J Control Release 2002;83:303-5.

92. Husseini GA, Diaz De La Rosa MA, Gabuji T, et al. Release of doxorubicin from unstabilized and stabilized micelles under the action of ultrasound. J Nanosci Nanotechnol 2007;7:1028-33.

93. Zeng Y, Pitt WG. A polymeric micelle system with a hydrolysable segment for drug delivery. J Biomater Sci Polym 2006;17: 591604.

94. Zeng Y, Pitt WG. Poly(ethylene oxide)-b-poly(nisopropylacrylamide) nanoparticles with crosslinked cores as drug carriers. J Biomat Sci Polym 2005;16:371-80.

95. Rapoport NY, Kennedy AM, Shea JE, et al. Controlled and targeted tumor chemotherapy by ultrasound-activated nanoemulsions/microbubbles. J Control Release 2009;138:268-76.

96. Basile L, Pignatello R, Passirani C. Active targeting strategies for anticancer drug nanocarriers. Curr Drug Deliv 2012;9:255-68.

97. Hasirci N. Micro and nano systems in biomedicine and drug delivery. In: Mozafari MR, ed. Nanomaterials and nanosystems for biomedical applications. Dordrecht: Springer; 2007:1-26.

98. Bohmer MR, Klibanov AL, Tiemann K, et al. Ultrasound triggered image-guided drug delivery. Eur J Radiol 2009;70: 242-53.

99. Maruyama K, Ishida O, Takizawa T, Moribe K. Possibility of active targeting to tumor tissues with liposomes. Adv Drug Deliv Rev 1999;40:89-102.

100. Torchilin V. Multifunctional and stimuli-sensitive pharmaceutical nanocarriers. Eur J Pharm Biopharm 2009;71:431-44.

101. Rapoport N. Physical stimuli-responsive polymeric micelles for anti-cancer drug delivery. Prog Polym Sci 2007;32:962-90. 
30 S. E. Ahmed et al.

102. Iakoubov LZ, Torchilin VP. A novel class of antitumor antibodies: nucleosome-restricted antinuclear autoantibodies (ANA) from healthy aged nonautoimmune mice. Oncol Res 1997;9:439-46.

103. Torchilin VP, Lukyanov AN, Gao Z, Papahadjopoulos-Sternberg B. Immunomicelles: targeted pharmaceutical carriers for poorly soluble drugs. Proc Natl Acad Sci USA 2003;100:6039-44.

104. Iakoubov L, Rokhlin O, Torchilin V. Anti-nuclear autoantibodies of the aged reactive against the surface of tumor but not normal cells. Immunol Lett 1995;47:147-9.

105. Iakoubov LZ, Torchilin VP. Nucleosome-releasing treatment makes surviving tumor cells better targets for nucleosome-specific anticancer antibodies. Cancer Detect Prev 1998;22:470-5.

106. Lukyanov AN, Gao Z, Torchilin VP. Micelles from polyethylene glycol/phosphatidylethanolamine conjugates for tumor drug delivery. J Control Release 2003;91:97-102.

107. Park JW, Kirpotin DB, Hong K, et al. Tumor targeting using antiher2 immunoliposomes. J Control Release 2001;74:95-113.

108. Husseini GA, Abdel-Jabbar NM, Mjalli FS, Pitt WG. Modeling and sensitivity analysis of acoustic release of Doxorubicin from unstabilized pluronic P105 using an artificial neural network model. Technol Cancer Res Treat 2007;6:49-56.

109. Husseini GA, Diaz De La Rosa MA, Richardson ES, et al. The role of cavitation in acoustically activated drug delivery. J Control Release 2005;107:253-61.

110. Silva R, Ferreira H, Little C, Cavaco-Paulo A. Effect of ultrasound parameters for unilamellar liposome preparation. Ultrason Sonochem 2010;17:628-32.

111. Stevenson-Abouelnasr D, Husseini GA, Pitt WG. Further investigation of the mechanism of Doxorubicin release from P105 micelles using kinetic models. Colloids Surf B 2007;55:59-66.

112. Husseini GA, Abdel-Jabbar NM, Mjalli FS, et al. Optimizing the use of ultrasound to deliver chemotherapeutic agents to cancer cells from polymeric micelles. J Franklin Inst 2011;348:1276-84.

113. Ugarenko M, Chan CK, Nudelman A, et al. Development of pluronic micelle-encapsulated doxorubicin and formaldehydereleasing prodrugs for localized anticancer chemotherapy. Oncol Res 2009; 17:283-99.

114. Zhang $\mathrm{H}$, Xia $\mathrm{H}$, Wang $\mathrm{J}$, Li $\mathrm{Y}$. High intensity focused ultrasoundresponsive release behavior of PLA-b-PEG copolymer micelles. J Control Release 2009;139:31-9.

115. Wang J, Pelletier $M$, Zhang $H$, et al. High-frequency ultrasoundresponsive block copolymer micelle. Langmuir 2009;25:13201-5.

116. Husseini GA, Stevenson-Abouelnasr D, Pitt WG, et al. Kinetics and thermodynamics of acoustic release of doxorubicin from nonstabilized polymeric micelles. Colloids Surf A 2010;359:8-24.

117. Husseini GA, De La Rosa MAD, Alaqqad EO, et al. Kinetics of acoustic release of doxorubicin from stabilized and unstabilized micelles and the effect of temperature. J Franklin Inst 2011;348: 125.

118. Diaz De La Rosa MA, Husseini GA, Pitt WG. Comparing microbubble cavitation at $500 \mathrm{kHz}$ and $70 \mathrm{kHz}$ related to micellar drug delivery using ultrasound. Ultrasonics 2013;53:377-86.

119. Diaz De La Rosa MA, Husseini GA, Pitt WG. Mathematical modeling of microbubble cavitation at $70 \mathrm{kHz}$ and the importance of the subharmonic in drug delivery from micelles. Ultrasonics 2013;53:97-110.

120. Husseini GA, Kherbeck L, Pitt WG, et al. Kinetics of ultrasonic drug delivery from targeted micelles. J Nanosci Nanotechnol 2014;14:1-6.

121. Husseini GA, Velluto D, Kherbeck L, et al. Investigating the acoustic release of doxorubicin from targeted micelles. Colloids Surf B 2013;101:153-5.

122. Rapoport N, Pitt WG, Sun H, Nelson JL. Drug delivery in polymeric micelles: from in vitro to in vivo. J Control Release 2003;91:85-95.

123. Husseini GA, Mjalli FS, Pitt WG, Abdel-Jabbar N. Using artificial neural networks and model predictive control to optimize
J Drug Target, Early Online: 1-33 acoustically assisted Doxorubicin release from polymeric micelles. Technol Cancer Res Treat 2009;8:479-88.

124. Diaz De La Rosa MA, Husseini GA, Pitt WG. Comparing microbubble cavitation at $500 \mathrm{kHz}$ and $70 \mathrm{kHz}$ related to micellar drug delivery using ultrasound. Ultrasonics 2012;53:377-86.

125. Diaz De La Rosa MA, Husseini GA, Pitt WG. Mathematical modeling of microbubble cavitation at $70 \mathrm{kHz}$ and the importance of the subharmonic in drug delivery from micelles. Ultrasonics 2012;53:97-110.

126. Husseini GA, Pitt WG, Christensen DA, Dickinson DJ. Degradation kinetics of stabilized Pluronic micelles under the action of ultrasound. J Control Release 2009;138:45-8.

127. Marin A, Muniruzzaman M, Rapoport N. Acoustic activation of drug delivery from polymeric micelles: effect of pulsed ultrasound. J Control Release 2001;71:239-49.

128. Marin A, Muniruzzaman M, Rapoport N. Mechanism of the ultrasonic activation of micellar drug delivery. J Control Release 2001;75:69-81.

129. Husseini GA, Runyan CM, Pitt WG. Investigating the mechanism of acoustically activated uptake of drugs from Pluronic micelles. BMC Cancer 2002;2:20.

130. Pruitt JD, Pitt WG. Sequestration and ultrasound-induced release of doxorubicin from stabilized Pluronic P105 micelles. Drug Deliv 2002;9:253-8.

131. Rapoport N, Marin A, Luo Y, et al. Intracellular uptake and trafficking of Pluronic micelles in drug-sensitive and MDR cells: effect on the intracellular drug localization. J Pharm Sci 2002;91: 157-70.

132. Husseini GA, O'Neill KL, Pitt WG. The comet assay to determine the mode of cell death for the ultrasonic delivery of doxorubicin to human leukemia (HL-60 Cells) from Pluronic P105 micelles. Technol Cancer Res Treat 2005;4:707-11.

133. Howard B, Gao A, Lee S-W, et al. Ultrasound-enhanced chemotherapy of drug-resistant breast cancer tumors by micellarencapsulated paclitaxel. Am J Drug Deliv 2006;4:97-104.

134. Loverock P, Ter Haar G, Ormerod MG, Imrie PR. The effect of ultrasound on the cytotoxicity of adriamycin. Br J Radiol 1990;63: $542-6$.

135. Carter SK. Adriamycin - a review. J Natl Cancer Inst 1975;55: 1265-74.

136. Miura S, Tachibana K, Okamoto T, Saku K. In vitro transfer of antisense oligodeoxynucleotides into coronary endothelial cells by ultrasound. Biochem Biophys Res Commun 2002;298:587-90.

137. Ogawa K, Tachibana K, Uchida T, et al. High-resolution scanning electron microscopic evaluation of cell-membrane porosity by ultrasound. Med Electron Microsc 2001;34:249-53.

138. Sivakumar M, Tachibana K, Pandit AB, et al. Transdermal drug delivery using ultrasound-theory, understanding and critical analysis. Cell Mol Biol (Noisy-le-grand) 2005;51:OL767-84.

139. Tachibana K, Uchida T, Ogawa K, et al. Induction of cellmembrane porosity by ultrasound. Lancet 1999;353:1409.

140. Tachibana K, Uchida T, Tamura K, et al. Enhanced cytotoxic effect of Ara-C by low intensity ultrasound to HL-60 cells. Cancer Lett 2000;149:189-94.

141. Taniyama Y, Tachibana K, Hiraoka K, et al. Development of safe and efficient novel nonviral gene transfer using ultrasound: enhancement of transfection efficiency of naked plasmid DNA in skeletal muscle. Gene Ther 2002;9:372-80.

142. Taniyama Y, Tachibana K, Hiraoka K, et al. Local delivery of plasmid DNA into rat carotid artery using ultrasound. Circulation 2002;105:1233-9.

143. Yamashita N, Tachibana K, Ogawa K, et al. Scanning electron microscopic evaluation of the skin surface after ultrasound exposure. Anat Rec 1997;247:455-61.

144. Saito K, Miyake K, Mcneil PL, et al. Plasma membrane disruption underlies injury of the corneal endothelium by ultrasound. Exp Eye Res 1999;68:431-7. 
DOI: 10.3109/1061186X.2014.954119

145. Prentice P, Cuschierp A, Dholakia K, et al. Membrane disruption by optically controlled microbubble cavitation. Nat Phys 2005;1: 107-10.

146. Stringham SB, Murray BK, O'neill KL, et al. Mechanism of targeted chemotherapeutic delivery using ultrasound. CA, USA: 96th Annual Meeting of the American Association for Cancer Research Anaheim; 2005.

147. Stringham SB, Viskovska MA, Richardson ES, et al. Overpressure suppresses ultrasonic-induced drug uptake. Ultrasound Med Biol 2009;35:409-15.

148. Bailey MR, Couret LN, Sapozhnikov OA, et al. Use of overpressure to assess the role of bubbles in focused ultrasound lesion shape in vitro. Ultrasound Med Biol 2001;27:695-708.

149. Richardson ES, Pitt WG, Woodbury DJ. The role of cavitation in liposome formation. Biophys J 2007;93:4100-7.

150. Schlicher RK, Hutcheson JD, Radhakrishna H, et al. Changes in cell morphology due to plasma membrane wounding by acoustic cavitation. Ultrasound Med Biol 2010;36:677-92.

151. Schlicher RK, Radhakrishna H, Tolentino TP, et al. Mechanism of intracellular delivery by acoustic cavitation. Ultrasound Med Biol 2006;32L:915-24.

152. Zhou Y, Kumon RE, Cui J, Deng CX. The size of sonoporation pores on the cell membrane. Ultrasound Med Biol 2009;35: 175660.

153. Meijering BD, Juffermans LJ, Van Wamel A, et al. Ultrasound and microbubble-targeted delivery of macromolecules is regulated by induction of endocytosis and pore formation. Circ Res 2009;104: 679-87.

154. Hauser J, Ellisman M, Steinau HU, et al. Ultrasound enhanced endocytotic activity of human fibroblasts. Ultrasound Med Biol 2009;35:2084-92.

155. Chen L, Sha X, Jiang X, et al. Pluronic P105/F127 mixed micelles for the delivery of docetaxel against Taxol-resistant non-small cell lung cancer: optimization and in vitro, in vivo evaluation. Int $\mathrm{J}$ Nanomedicine 2013;8:73-84.

156. Nelson JL. Ultrasonically enhanced drug delivery of doxorubicin in vivo from stabilized pluronic micelle carriers. Provo, UT, Brigham: Young University; 2002.

157. Nelson JL, Roeder BL, Carmen JC, et al. Ultrasonically activated chemotherapeutic drug delivery in a rat model. Cancer Res 2002; 62:7280-3.

158. Rapoport NY, Christensen DA, Fain HD, et al. Ultrasoundtriggered drug targeting of tumors in vitro and in vivo. Ultrasonics 2004;42:943-50.

159. Gao Z, Fain HD, Rapoport N. Ultrasound-enhanced tumor targeting of polymeric micellar drug carriers. Mol Pharm 2004; 1:317-30.

160. Gao ZG, Fain HD, Rapoport N. Controlled and targeted tumor chemotherapy by micellar-encapsulated drug and ultrasound. J Control Release 2005;102:203-22.

161. Myhr G, Moan J. Synergistic and tumour selective effects of chemotherapy and ultrasound treatment. Cancer Lett 2006;232: 206-13.

162. Staples BJ. Pharmacokinetics of ultrasonically-released, micelleencapsulated doxorubicin in the rat model and its effect on tumor growth. Provo. UT: Brigham Young University; 2007.

163. Staples BJ, Roeder BL, Husseini GA, et al. Role of frequency and mechanical index in ultrasonic-enhanced chemotherapy in rats. Cancer Chemother Pharmacol 2009;64:593-600.

164. Staples BJ, Pitt WG, Roeder BL. Distribution of doxorubicin in rats undergoing ultrasonic drug delivery. J Pharm Sci 2010;99: 312231.

165. Gao Z, Kennedy AM, Christensen DA, Rapoport NY. Drug-loaded nano/microbubbles for combining ultrasonography and targeted chemotherapy. Ultrasonics 2008;48:260-70.

166. Hasanzadeh H, Mokhtari-Dizaji M, Bathaie SZ, Hassan ZM. Effect of local dual frequency sonication on drug distribution from polymeric nanomicelles. Ultrason Sonochem 2011;18:1165-71.
Release of chemotherapeutic drugs from micelles \& liposomes 31

167. Staples BJ, Roeder BL, Pitt WG. Quantification of doxorubicin concentration in rat tissues using polymeric micelles in ultrasonicdrug delivery. Pittsburgh, USA: Annual Meeting of the Society for Biomaterials; 2006.

168. Mozafari MR, Khosravi-Darani K. An overview of liposomederived nanocarrier technologies. In: Mozafari MR, ed. Nanomaterials and nanosystems for biomedical applications. Dordrecht: Springer; 2007:113-23.

169. Sipai ABM, Yadav V, Mamatha Y, Prasanth VV. Liposomes: an Overview. J Pharm Sci Innov 2012;1:13-21.

170. Pinheiro M, Lucio M, Lima JL, Reis S. Liposomes as drug delivery systems for the treatment of TB. Nanomedicine (Lond) 2011;6:1413-28.

171. Barenholz Y. Amphipathic weak base loading into preformed liposomes having a transmembrane ammonium ion gradient: from the bench to approved doxil. In: Gregoriadis G, ed. Liposome technology. Volume II. Entrapment of drugs and other materials into liposomes. New York: Informa Healthcare; 2006:1-25.

172. Gabizon A, Price DC, Huberty J, et al. Effect of liposome composition and other factors on the targeting of liposomes to experimental tumors: biodistribution and imaging studies. Cancer Res 1990;50:6371-8.

173. Willis M, Forssen E. Ligand-targeted liposomes. Adv Drug Deliv Rev 1998;29:249-71.

174. Kirby C, Clarke J, Gregoriadis G. Effect of the cholesterol content of small unilamellar liposomes on their stability in vivo and in vitro. Biochem J 1980;186:591-8.

175. Lee KD, Hong K, Papahadjopoulos D. Recognition of liposomes by cells: in vitro binding and endocytosis mediated by specific lipid headgroups and surface charge density. Biochem Biophys Acta 1992;1103:185-97.

176. Banno Y, Ohki K, Morita T, et al. Involvement of the membrane fluidity of lactosylceramide-targeted liposomes in their intrahepatic uptake. Biochem Int 1986;12:865-71.

177. Emanuel N, Kedar E, Bolotin EM, et al. Preparation and characterization of doxorubicin-loaded sterically stabilized immunoliposomes. Pharm Res 1996;13:352-9.

178. Mori A, Klibanov AL, Torchilin VP, Huang L. Influence of the steric barrier activity of amphipathic poly(ethyleneglycol) and ganglioside GM1 on the circulation time of liposomes and on the target binding of immunoliposomes in vivo. FEBS Lett 1991;284: 263-6.

179. Andresen TL, Jensen SS, Jorgensen K. Advanced strategies in liposomal cancer therapy: problems and prospects of active and tumor specific drug release. Prog Lipid Res 2005;44:68-97.

180. Papahadjopoulos D, Allen TM, Gabizon A, et al. Sterically stabilized liposomes: improvements in pharmacokinetics and antitumor therapeutic efficacy. Proc Natl Acad Sci USA 1991; $88: 11460-4$

181. Allen TM. Long-circulating (sterically stabilized) liposomes for targeted drug delivery. Trends Pharmacol Sci 1994;15:215-20.

182. Lu WL, Qi XR, Zhang Q, et al. A pegylated liposomal platform: pharmacokinetics, pharmacodynamics, and toxicity in mice using doxorubicin as a model drug. J Pharmacol Sci 2004;95:381-9.

183. Lin HY, Thomas JL. PEG-Lipids and oligo(ethylene glycol) surfactants enhance the ultrasonic permeabilizability of liposomes. Langmuir 2003;19:1098-105.

184. Park YS. Tumor-directed targeting of liposomes. Biosci Rep 2002; 22:267-81.

185. Huang SL. Liposomes in ultrasonic drug and gene delivery. Adv Drug Deliv Rev 2008;60:1167-76.

186. Huang SL, Macdonald RC. Acoustically active liposomes for drug encapsulation and ultrasound-triggered release. Biochem Biophys Acta 2004;1665:134-41.

187. Lattin JR, Pitt WG, Belnap DM, Husseini GA. Ultrasound-induced calcein release from eLiposomes. Ultrasound Med Biol 2012;38: 2163-73.

188. Torchilin VP. Recent advances with liposomes as pharmaceutical carriers. Nat Rev Drug Discov 2005;4:145-60. 
32 S. E. Ahmed et al.

189. Javadi M, Pitt WG, Belnap DM, et al. Encapsulating nanoemulsions inside eLiposomes for ultrasonic drug delivery. Langmuir 2012;28:14720-9.

190. Javadi M, Pitt WG, Tracy C, et al. Ultrasonic gene and drug delivery using eLiposomes. J Control Release 2013;167:92-100.

191. Lattin JR, Belnap DM, Pitt WG. Formation of eLiposomes as a drug delivery vehicle. Colloids Surf B 2012;89:93-100.

192. Lin CY, Javadi M, Belnap DM, et al. Ultrasound sensitive eLiposomes containing doxorubicin for drug targeting therapy. Nanomedicine 2014;10:67-76.

193. Sheeran PS, Dayton PA. Improving the performance of phasechange perfluorocarbon droplets for medical ultrasonography: current progress, challenges, and prospects. Scientifica 2014; 2014:579684 (1-24).

194. Ta T, Porter TM. Thermosensitive liposomes for localized delivery and triggered release of chemotherapy. J Control Release 2013;169:112-25.

195. Barenholz Y. Cholesterol and other membrane active sterols: from membrane evolution to "rafts"'. Prog Lipid Res 2002;41:1-5.

196. Jorgensen K, Mouritsen OG. Phase separation dynamics and lateral organization of two-component lipid membranes. Biophys J 1995;69:942-54.

197. Yatvin MB, Weinstein JN, Dennis WH, Blumenthal R. Design of liposomes for enhanced local release of drugs by hyperthermia. Science 1978;202:1290-3.

198. Barenholz Y, Cevc G. Structure and properties of membranes in physical chemistry of biological surfaces. New York: Marcel Dekker; 2000.

199. Cohen-Levi D. Ultrasound for targeted delivery of cytotoxic drugs from liposomes. Beer Sheva, Israel: Ben Gurion University; 2000.

200. Dromi S, Frenkel V, Luk A, et al. Pulsed-high intensity focused ultrasound and low temperature-sensitive liposomes for enhanced targeted drug delivery and antitumor effect. Clin Cancer Res 2007; 13:2722-7.

201. Schroeder A, Avnir Y, Weisman S, et al. Controlling liposomal drug release with low frequency ultrasound: mechanism and feasibility. Langmuir 2007;23:4019-25.

202. Chen $\mathrm{D}, \mathrm{Wu}$ J. An in vitro feasibility study of controlled drug release from encapsulated nanometer liposomes using high intensity focused ultrasound. Ultrasonics 2010;50:744-9.

203. Evjen TJ, Nilssen EA, Rognvaldsson S, et al. Distearoylphosphatidylethanolamine-based liposomes for ultrasound-mediated drug delivery. Eur J Pharm Biopharm 2010;75: 327-33.

204. Evjen TJ, Nilssen EA, Barnert S, et al. Ultrasound-mediated destabilization and drug release from liposomes comprising dioleoylphosphatidylethanolamine. Eur J Pharm Sci 2011;42: 3806 .

205. Ninomiya K, Kawabata S, Tashita H, Shimizu N. Ultrasoundmediated drug delivery using liposomes modified with a thermosensitive polymer. Ultrason Sonochem 2014;21:310-16.

206. Lin HY Thomas JL. Factors affecting responsivity of unilamellar liposomes to $20 \mathrm{kHz}$ ultrasound. Langmuir 2004;20:6100-6.

207. Evjen TJ, Hupfeld S, Barnert S, et al. Physicochemical characterization of liposomes after ultrasound exposure mechanisms of drug release. J Pharm Biomed Anal 2013;7879:118-22.

208. Singh R, Husseini GA, Pitt WG. Phase transitions of nanoemulsions using ultrasound: experimental observations. Ultrason Sonochem 2012;19:1120-5.

209. Pitt WG, Singh RN, Perez KX, et al. Phase transitions of perfluorocarbon nanoemulsion induced with ultrasound: a mathematical model. Ultrason Sonochem 2014;21:879-91.

210. Lentacker I, Geers B, Demeester J, et al. Design and evaluation of doxorubicin-containing microbubbles for ultrasound-triggered doxorubicin delivery: cytotoxicity and mechanisms involved. Mol Ther 2010;18:101-8.
J Drug Target, Early Online: 1-33

211. Ueno Y, Sonoda S, Suzuki R, et al. Combination of ultrasound and bubble liposome enhance the effect of doxorubicin and inhibit murine osteosarcoma growth. Cancer Biol Ther 2011;12:270-7.

212. Escoffre JM, Mannaris C, Geers B, et al. Doxorubicin liposomeloaded microbubbles for contrast imaging and ultrasoundtriggered drug delivery. IEEE Trans Ultrason Ferroelectr Freq Control 2013;60:78-87.

213. Afadzi M, Strand SP, Nilssen EA, et al. Mechanisms of the ultrasound-mediated intracellular delivery of liposomes and dextrans. IEEE Trans Ultrason Ferroelectr Freq Control 2013; 60:21-33.

214. Yan F, Li L, Deng Z, et al. Paclitaxel-liposome-microbubble complexes as ultrasound-triggered therapeutic drug delivery carriers. J Control Release 2013;166:246-55.

215. Chen CC, Wu SY, Finan JD, et al. An experimental study on the stiffness of size-isolated microbubbles using atomic force microscopy. IEEE Trans Ultrason Ferroelectr Freq Control 2013;60: 524-34.

216. Shih CP, Chen HC, Chen HK, et al. Ultrasound-aided microbubbles facilitate the delivery of drugs to the inner ear via the round window membrane. J Control Release 2013;167:167-74.

217. Li P, Zheng Y, Ran H, et al. Ultrasound triggered drug release from 10-hydroxycamptothecin-loaded phospholipid microbubbles for targeted tumor therapy in mice. J Control Release 2012;162: 34954.

218. Lindner JR. Microbubbles in medical imaging: current applications and future directions. Nat Rev Drug Discov 2004;3:527-32.

219. Krupka TM, Solorio L, Wilson RE, et al. Formulation and characterization of echogenic lipid-Pluronic nanobubbles. Mol Pharm 2009;7:49-59.

220. Endo-Takahashi Y, Negishi Y, Nakamura A, et al. pDNA-loaded Bubble liposomes as potential ultrasound imaging and gene delivery agents. Biomaterials 2013;34:2807-13.

221. Yuh EL, Shulman SG, Mehta SA, et al. Delivery of systemic chemotherapeutic agent to tumors by using focused ultrasound: study in a murine model. Radiology 2005;234:431-7.

222. Frenkel V, Etherington A, Greene M, et al. Delivery of liposomal doxorubicin (Doxil) in a breast cancer tumor model: investigation of potential enhancement by pulsed-high intensity focused ultrasound exposure. Acad Radiol 2006;13:469-79.

223. Pitt WG, Husseini GA, Roeder BL, et al. Preliminary results of combining low frequency low intensity ultrasound and liposomal drug delivery to treat tumors in rats. J Nanosci Nanotechnol 2011; 11:1866-70.

224. Gabizon A, Martin F. Polyethylene glycol-coated (pegylated) liposomal doxorubicin. Drugs 1997;54:15-21.

225. Gabizon AA, Barenholz Y, Bialer M. Prolongation of the circulation time of doxorubicin encapsulated in liposomes containing a polyethylene glycol-derivatized phospholipid: pharmacokinetic studies in rodents and dogs. Pharm Res 1993;10: 703-8.

226. Working PK, Newman MS, Huang SK, et al. Pharmacokinetics, biodistribution and therapeutic efficacy of doxorubicin encapsulated in Stealth liposomes (Doxil). J Liposome Res 1994;4: 667-87.

227. Working PK, Dayan AD. Pharmacological-toxicological expert report. CAELYX. (Stealth liposomal doxorubicin $\mathrm{HCl}$ ). Hum Exp Toxicol 1996;15:751-85.

228. Working PK, Newman MS, Sullivan T, Yarrington J. Reduction of the cardiotoxicity of doxorubicin in rabbits and dogs by encapsulation in long-circulating pegylated liposomes. J Pharmacol Exp Ther 1999;289:1128-33.

229. Treat LH, Mcdannold N, Vykhodtseva N, et al. Targeted delivery of doxorubicin to the rat brain at therapeutic levels using MRIguided focused ultrasound. Int J Cancer 2007;121:901-7.

230. Nhan T, Burgess A, Cho EE, et al. Drug delivery to the brain by focused ultrasound induced blood-brain barrier disruption: quantitative evaluation of enhanced permeability of cerebral 
vasculature using two-photon microscopy. J Control Release 2013;172: 274-80.

231. Aryal M, Vykhodtseva N, Zhang Y-Z, et al. Multiple treatments with liposomal doxorubicin and ultrasound-induced disruption of blood-tumor and blood-brain barriers improve outcomes in a rat glioma model. J Control Release 2013;169:103-11.

232. Evjen TJ, Hagtvet E, Moussatov A, et al. In vivo monitoring of liposomal release in tumours following ultrasound stimulation. Eur J Pharm Biopharm 2013;84:526-31.

233. Rizzitelli S, Giustetto P, Boffa C. In vivo MRI visualization of release from liposomes triggered by local application of pulsed low-intensity non-focused ultrasound. Nanomedicine 2014;21: $310-16$.

234. Allen TM, Cullis PR. Liposomal drug delivery systems: from concept to clinical applications. Adv Drug Deliv Rev 2013;65: 3648.

235. Duggan ST, Keating GM. Pegylated liposomal doxorubicin: a review of its use in metastatic breast cancer, ovarian cancer, multiple myeloma and AIDS-related Kaposi's sarcoma. Drugs 2011;71:2531-58.

236. Perez AT, Domenech GH, Frankel C, Vogel CL. Pegylated liposomal doxorubicin (Doxil) for metastatic breast cancer: the Cancer Research Network, Inc., experience. Cancer Invest 2002;2: 22-9.

237. Chou HH, Wang KL, Chen CA, et al. Pegylated liposomal doxorubicin (Lipo-Dox) for platinum-resistant or refractory epithelial ovarian carcinoma: a Taiwanese gynecologic oncology group study with long-term follow-up. Gynecol Oncol 2006;101: 423-8.

238. Shields AF, Lange LM, Zalupski MM. Phase II study of liposomal doxorubicin in patients with advanced colorectal cancer. Am J Clin Oncol 2001;24:96-8.

239. Mazurchuk R, Glaves D, Raghavan D. Magnetic resonance imaging of response to chemotherapy in orthotopic xenografts of human bladder cancer. Clin Cancer Res 1997;3: 1635-41.

240. Deng L, Ke X, He Z, et al. A MSLN-targeted multifunctional nanoimmunoliposome for MRI and targeting therapy in pancreatic cancer. Int J Nanomedicine 2012;7:5053-65.

241. Soloman R, Gabizon AA. Clinical pharmacology of liposomal anthracyclines: focus on pegylated liposomal Doxorubicin. Clin Lymphoma Myeloma 2008;8:21-32.

242. Vail DM, Amantea MA, Colbern GT, et al. Pegylated liposomal doxorubicin: proof of principle using preclinical animal models and pharmacokinetic studies. Semin Oncol 2004;31:16-35.

243. Harrington KJ, Lewanski C, Northcote AD, et al. Phase II study of pegylated liposomal doxorubicin (Caelyx) as induction chemotherapy for patients with squamous cell cancer of the head and neck. Eur J Cancer 2001;37:2015-22.

244. Gordon AN, Granai CO, Rose PG, et al. Phase II study of liposomal doxorubicin in platinum- and paclitaxel-refractory epithelial ovarian cancer. J Clin Oncol 2000;18:3093-100.

245. Johnston SR, Gore ME. Caelyx: phase II studies in ovarian cancer. Eur J Cancer 2001;37:S8-14.

246. Kudoh K, Takano M, Kouta H, et al. Effects of bevacizumab and pegylated liposomal doxorubicin for the patients with recurrent or refractory ovarian cancers. Gynecol Oncol 2011;122:233-7.

247. Muggia FM, Hainsworth JD, Jeffers S, et al. Phase II study of liposomal doxorubicin in refractory ovarian cancer: antitumor activity and toxicity modification by liposomal encapsulation. $\mathrm{J}$ Clin Oncol 1997;15:987-93.

248. Thigpen JT, Aghajanian CA, Alberts DS, et al. Role of pegylated liposomal doxorubicin in ovarian cancer. Gynecol Oncol 2005;96: $10-18$.

249. Hollis CP, Weiss HL, Leggas M, et al. Biodistribution and bioimaging studies of hybrid paclitaxel nanocrystals: lessons learned of the EPR effect and image-guided drug delivery. J Control Release 2013;172:12-21. 